\title{
Does cycling infrastructure reduce stress biomarkers in cyclists? A comparison of five European cities
}

Inaian Pignatti Teixeiraa,*, Antônio Nélson Rodrigues da Silva ${ }^{\mathrm{a}}$, Tim Schwanen ${ }^{\mathrm{b}}$, Gustavo GarciaManzatoc LindaDörrzapf $^{d}$, PeterZeile ${ }^{e}$, LucDekoninck $^{\dagger}$, DickBotteldooren ${ }^{\dagger}$

a São Carlos School of Engineering, University of São Paulo, São Carlos, Brazil

b Transport Studies Unit, University of Oxford, Oxford, United Kingdom

c School of Engineering, São Paulo State University, Bauru, Brazil

d Institute of Spatial Planning, TU Wien, Vienna, Austria

e Institute of Urban and Landscape Design, Karlsruhe Institute of Technology, Karlsruhe, Germany

f Information Technology, Acoustics Group, Ghent University, Ghent, Belgium

\section{Abstract}

There is substantial evidence that the environment has an important impact on the use of bicycles. Changes in the built environment, such as cycling infrastructure provision, usually aim at improving the efficiency, enjoyability and safety of cycling. They can also shape affective responses, for instance by triggering or preventing stress situations during cycling. The repeated occurrence of intensely stressful events may make actual cyclists more likely to abandon cycling and deter prospective cyclists from actually taking up this form of mobility. Therefore, using a novel approach, based on stress biomarker measurements obtained directly from cyclists, the objective of this study is to investigate the relationship between urban environment and cyclists' stress. It also investigates if different types of cycling infrastructures in the contexts of two different countries and in five different cities have different relationships with stress. Using a stress sensor, 70 young adults were invited to cycle along a standard route in Oxford, London (the United Kingdom), Amsterdam, Houten and Groningen (the Netherlands). These routes were around $6 \mathrm{~km}$ long and had a wide range of characteristics. Multilevel logistic regression analysis indicates that the probability of stressful events occurring is significantly lower on physically segregated cycle paths than on cycle paths on streets, with cycling on general use streets falling in-between these extremes. We also find higher probabilities of stress for primary roads compared to tertiary roads, at intersections than on straight roads, on cobbled and off-road surfaces compared to asphalt, and in noisier places. Models for the individual cities suggested that the relationship between cycling infrastructure and the likelihood of stressful events occurring may depend on the local context. Only for noise conditions, intersection types and cycling infrastructures were the effects consistent across the cities. These findings may be useful for urban infrastructure planning and management, indicating specific attributes that should be adjusted to make cycling less stressful.

Keywords: stress; cycling; cycling infrastructure; cycle lane; cycle path

\section{Highlights}

- The presence of cycling infrastructure is associated with stress while cycling

- $\quad$ Physical segregation between cyclists and vehicles reduces the likelihood of stress

- The likelihood of stress increases at intersections and at noisy places 
- $\quad$ Each city studied presented specificities among the environment stressors 


\section{Introduction}

Cycling is seen as a sustainable mode of transport and a good choice for a transition towards low-carbon, energyefficient urban mobility systems. In addition, cycling can improve population health (Oja et al., 2011) and may have the additional benefits of avoiding the external costs of motorized transport associated with injuries, air and noise pollution, and community severance (Public Health England, 2014).

Interventions aimed at increasing commuter cycling have mainly been focused on individual/group approaches and environmental actions (Stewart et al., 2015). That is, while interventions focusing on individual choices and behavior usually provide information, advice and/or even free bicycles to encourage cycling, environmental ones aim to create more bicycle-friendly places. Although environmental interventions may present smaller effect sizes, they appear to have more public health significance, reaching many more people in everyday life situations (Stewart et al., 2015). It is important to emphasize that changes to the environment can affect multiple aspects and qualities of cycling, not only its efficiency and safety, but also its enjoyability (Pritchard, 2018). Thus, measuring affective responses induced by the environment during cycling is essential to understand, optimize and promote bicycle use. In this sense, affective responses could be a general psychological state of an individual, including emotions and mood, describing the subjective experience, and considering both positive and negative dimensions (Haile et al., 2014).

One important affective response, we suggest, is the (prospective) experience of stress during cycling, characterized by the difference between the stress that people actually experience whilst in the midst of a ride and the stress they anticipate or expect to experience if they decide to get on a bike. In addition, repeated occurrence of intensely stressful events may make actual cyclists more likely to abandon cycling and deter prospective cyclists from taking up this form of mobility. Several factors associated with stress have been recognized in the psychology and sociology literatures, including internal and external environment perturbations, future expectancy, negative neighborhood characteristics, and even social threats (Oken et al., 2015; Zhang, 2018). However, it is important to highlight that only a few studies have tested the relationship between bicycle commuting and stress in adults (Avila-Palencia et al., 2017; Doorley et al., 2015; Kaplan and Prato, 2016; H. Wang et al., 2016). Even fewer have questioned whether there is any relationship between environmental factors and stress, using physiological signals (Fitch et al., 2017; Kyriakou et al., 2019; Nuñez et al., 2018).

Over the last few years, a new approach has been developed to access autonomic responses to physiological stress in cycling (further discussed in Section 2.1), based on measurements of stress biomarkers obtained directly from cyclists (Caviedes et al., 2017; Fitch et al., 2017; Liu et al., 2016; Zeile et al., 2016). These stressful events are related to safety and security, since, in general, stress is associated with reactions of the organism aiming to survive or to avoid pain and discomfort (Ulrich-Lai and Herman, 2009). 
In general, these studies assessed stress using electrocardiogram, electrodermal activity (galvanic skin response), skin temperature or heart rate variability. Specifically regarding the relationship between environmental factors and stress while cycling, they found lower levels of stress during off-peak than during peak hours, at separated cycling infrastructure than on shared roadways (Caviedes et al., 2017; Liu et al., 2016), and on local streets than on arterial roads (Fitch et al., 2017). Stress tended to occur more often on signalized intersections compared to straight segments (Caviedes et al., 2017; Liu et al., 2016). Stress was also likely to occur when cyclists were close to a large number of vehicles, were overtaken by cars that did not respect the legal safety distance, experienced long waiting times at crossroads, or rode in heavy traffic (Zeile et al., 2016).

Thus, research investigating the relationship between cycling infrastructures and stress biomarkers is relevant and can contribute both to scientific knowledge and to the planning/implementation of public policies. These public policies, based on scientific evidence, may be attractive, effective and efficient in promoting cycling as a means of transport. In addition to the studies mentioned above, we propose a study with a broader range of environmental characteristics, a larger sample, in different contexts of countries and cities and, finally, with a robust approach to data analysis. Therefore, this study aims to investigate the relationship between the urban environment and cyclists' stress. It also investigates if different types of cycling infrastructures in two different countries and in five different cities' contexts have a different relationship with stress.

\section{Theoretical framework}

\subsection{Stress, skin conductance and skin temperature}

Historically, stress has been defined as a reaction in the form of a shift from a calm state to an excited state for the purpose of preserving the integrity of the organism (Healey and Picard, 2005). It is considered an unpleasant emotional state and tends to emerge when people experience situations they perceive as highly challenging or physically threatening (Lovallo, 2015; Villarejo et al., 2012). In such situations, some changes happen to people’s bodies such as pupil dilation, increased heart rate and contractility, vasoconstriction, bronchodilation, sweating, decreased motility of the digestive system, secretion of the epinephrine and cortisol (McCorry, 2007). All these changes are made to prepare the body for strenuous physical activity.

Kyriakou et al. (2019) reviewed relevant literature about how to detect the physiological signals of stress and found a wide range of approaches, including studies in the laboratory and the real world. The more frequently examined physiological signals were: galvanic skin response, skin temperature, blood volume pulse, respiration, electrical activity in the brain or the heart, and heart rate variability. In some cases, these signals were measured separately, and in others several were examined in combination, presenting an accuracy between $74.5 \%$ to $99.5 \%$. After that review, the authors proposed detecting "moments of stress" using a combination of skin conductance and skin temperature, compared to the subjectively perceived stress levels and emotions, collected through an eDiary smartphone app. In the laboratory, they detected $77 \%$ of stress moments and, during a real-world cycling task, the algorithm detected $84 \%$ of stress moments correctly, showing high correlations between physiologically 
measured (wearable sensors), self-reported (questionnaire), and recorded (video) stress events. On the other hand, at the laboratory test, Kyriakou et al. (2019) detected the occurrence of false positives stress events, although the study did not specify the quantity. It should be noted that the same kind of issue could happen during a real-world cycling test.

Finally, it is important to highlight that, although stress can be a complex reaction consisting of physiological and psychological (i.e., cognitive, affective and behavioral) components (Zhang, 2018), in this publication, we use the term "stress" to refer to an increase in skin conductance and a decrease in skin temperature as an indication of an emotional construct.

\subsection{Stress and cycling}

Considering the vast literature on objective and subjectively experienced safety in relation to cycling, we can derive expectations about which factors and conditions can trigger stressful events during cycling, once the safety issues can affect the integrity of the cyclist, emerging a stress condition. Thus, when evaluating cyclists' safety, various aspects are generally considered. Examining the connections between the physical environment and adult physical activity, several studies have identified numerous and complex interactions, such as population density, connectivity, and land use mix (Saelens et al., 2003; H. Wang et al., 2016). The urban environment plays a significant role in influencing levels of cycling as cyclists are seen as vulnerable road users. Thus, some environment characteristics, for example bike lanes, when improving safety, could act as motivators for cycling (Wang et al., 2016). Specifically related to cycling, some urban environment characteristics are recognized as associated with stress, for instance, road characteristics, cycling infrastructure, noise and vibration. Thus, we selected seven urban environment attributes that were reported, linked directly or indirectly to a possible stress episode while cycling. They are: street hierarchy, street direction, intersection, surface, road work, noise and type of road.

A literature review about the impact of transportation infrastructure on bicycling injuries and crashes indicated that major roads are more hazardous than minor roads (Reynolds et al., 2009). Some other studies also tried to find the relationship between cycling safety and street direction, given that bidirectional streets could increase the complexity of the interactions because drivers must scan more directions in a short period of time. In addition, there are some indications that, for bidirectional streets, the likelihood of frontal crashes between cyclists increases (Methorst et al., 2017; Schepers et al., 2017).

Other possible factors that could affect stress are intersections and the road surface. Intersections are complex zones as there is a possibility for both cyclists and drivers to change direction. Thus, some studies have indicated a higher frequency of crashes and cyclist injuries in those places (Aldred et al., 2018; Brüde and Larsson, 1993; Miranda-Moreno et al., 2011; Wang and Nihan, 2004; Williams, 2015). Although the lack of smoothness can contribute to the safety condition (American Association of and State Highway and Transportation Officials, 2012), the kind of surface substantially affects the cyclists' comfort because more vibration results in less comfort 
for the rider (Olieman et al., 2012). The concomitant reduction in safety and comfort could be an important stress source while cycling.

Along city streets, roadworks can result in unsafe places for pedestrians and cyclists, as part of or the entire road is occupied for work usually repairing the road surface and/or work near passageways. Owing to that, the United Kingdom government produced some Construction Guidance and Code of Practice to minimize the negative impacts of roadwork activities. Especially related to cyclists, the recommendation is to provide temporary traffic management at construction sites, to support the continued increase in cycling and to promote safe use of this transport mode. However, hazardous and probably stressful situations could happen in those places such as pinch points, long diversion routes, poor surfaces, conflicts with pedestrians and others.

Concerning noise, Nuñez et al. (2018) have shown that high noise levels were associated with a higher likelihood of a stressful event while cycling. The literature also described other possible adverse effects of road traffic noise on human health, such as irritation and annoyance, cardiovascular disease, risk of stroke, diabetes, hypertension and loss of hearing (Singh et al., 2018). Specifically for cyclists, traffic noise may also affect concentration (Suetomi and Niibe, 2002) and the motivation to cycle (Winters et al., 2011).

Specifically related to roads, special attention can be given to cycling infrastructures. Implementing improved cycling infrastructure significantly contributes to improvements in cycling safety (Pucher and Buehler, 2016), reducing the fear of cycling (Garrard et al., 2008; Winters et al., 2011; Yang and Matthews, 2010) and injuries (Moritz, 1998; Rodgers, 1997).

Previous studies found that cyclists' levels of comfort are inversely associated with the proximity to motorized traffic (Chuang et al., 2013; Kim et al., 2007), preferring to ride on separate bike paths (Hunt and Abraham, 2007; Sener et al., 2009; Wardman et al., 2007; Winters et al., 2011), and opposing to high speed and high traffic volume streets (Misra et al., 2015). This preference could be because riding on these specific lanes tend to be safer, thus leading to a reduction in crash rates (Lusk et al., 2013, 2011; Teschke et al., 2012) and lower cycling injury risk (Reynolds et al., 2009; Thomas et al., 2013). These injuries reductions, when riding on bicycle-specific infrastructures, vary between 9\% and 50\% (Lusk et al., 2011; Reynolds et al., 2009).

Finally, it is also important to consider the demographic factors. People of different ages, gender or socioeconomic status may need different traffic safety guidelines (Vanparijs et al., 2015). For example, women and the elderly appear to be especially vulnerable to traffic-related hazards (Garrard et al., 2008). Other studies indicate that women are more influenced by questions of personal safety in traffic than men (Oja et al., 1998) and, in general, cycle less as well (de Geus et al., 2014). Related to age, cyclists younger than 30 years and older than 65 years of age present the highest risk of being involved in a crash (Useche et al., 2018).

Based on the factors identified above, we hypothesized that the likelihood of stress would be higher when the cyclist rides on streets shared with other vehicles, without a cycle lane, on primary roads, at intersections, on poor surfaces, bidirectional streets, segments with roadworks and noisier ones. In addition, we theorized that females and riders with less cycling experience may be more susceptible to stress as well. 


\section{Methods}

To analyze the relationship between cycling infrastructures and stress, we selected five European cities in two different countries and invited participants to ride along a standard route carrying a Smartband and a noise sensor. The cities selected were: Oxford and London (the United Kingdom); Amsterdam, Houten and Groningen (the Netherlands). The rationale of this selection was to have cities of different sizes, cultures, cycling infrastructures, levels of bicycle use and automobility, traffic, etc.

For each city, a standard route was designed by the research team, following five steps: 1) Mapping all cycling infrastructures using online databases (Open Street Maps and local government websites); 2) Categorizing the cycling infrastructures, creating six categories, based on combining types of cycling infrastructures (with or without physical segregation) and hierarchical levels of the road (primary, secondary and tertiary); 3) Selecting a cycling infrastructure sample, picking at least one for each six categories created on the previous step; 4) Defining the route's starting point. With a view to facilitating the recruitment of our target participants (young adults), the starting point of each route was selected at a public place of interest (churches/squares) in the neighborhood with the highest density of university students during daytime in each city; 5) After performing the previous four steps, the team created the standard route, joining all infrastructures selected at steps 3 and 4. For the British cities, routes were in a clockwise direction and, in the Netherlands, counterclockwise. The routes were from 6.2 $\mathrm{km}$ long in London and Amsterdam to $6.5 \mathrm{~km}$ long in Oxford and all the participants in a city traveled the same route. The final routes selected are presented in Figure 1.

\subsection{Participants}

The participants were invited to take part in the study using three different methods: 1) online advertisements (social media and local websites), 2) paper-based advertisements and 3) face-to-face invitations in common university areas and streets. The inclusion criteria for participants were that they had to be: 18-30 years old; healthy; and able to ride a bike. The exclusion criterion was not having cycled at least twelve times in the last three months. These criteria were adopted to select people engaged in cycling, avoiding exposing non-competent cyclists (i.e. those who are unfamiliar with local traffic and vulnerable people such as children, teenagers and elderly) to risks.

All procedures were in accordance with the Helsinki Declaration on using humans as research subjects. The Brazilian Research Ethics Committee approved this study (Protocol number: 2.323.525), and the participants were informed about the procedures and risks before giving written consent.

The final sample had 70 participants, comprising 14 participants in Oxford, 14 in London, 16 in Houten, 15 in Groningen and 11 in Amsterdam. In general, the sample mainly consisted of male participants (61.4\%), people aged between 25 and 30 years old (68.6\%), with a higher education level - undergraduate or postgraduate $(77.1 \%)$ and from 19 different nationalities. 


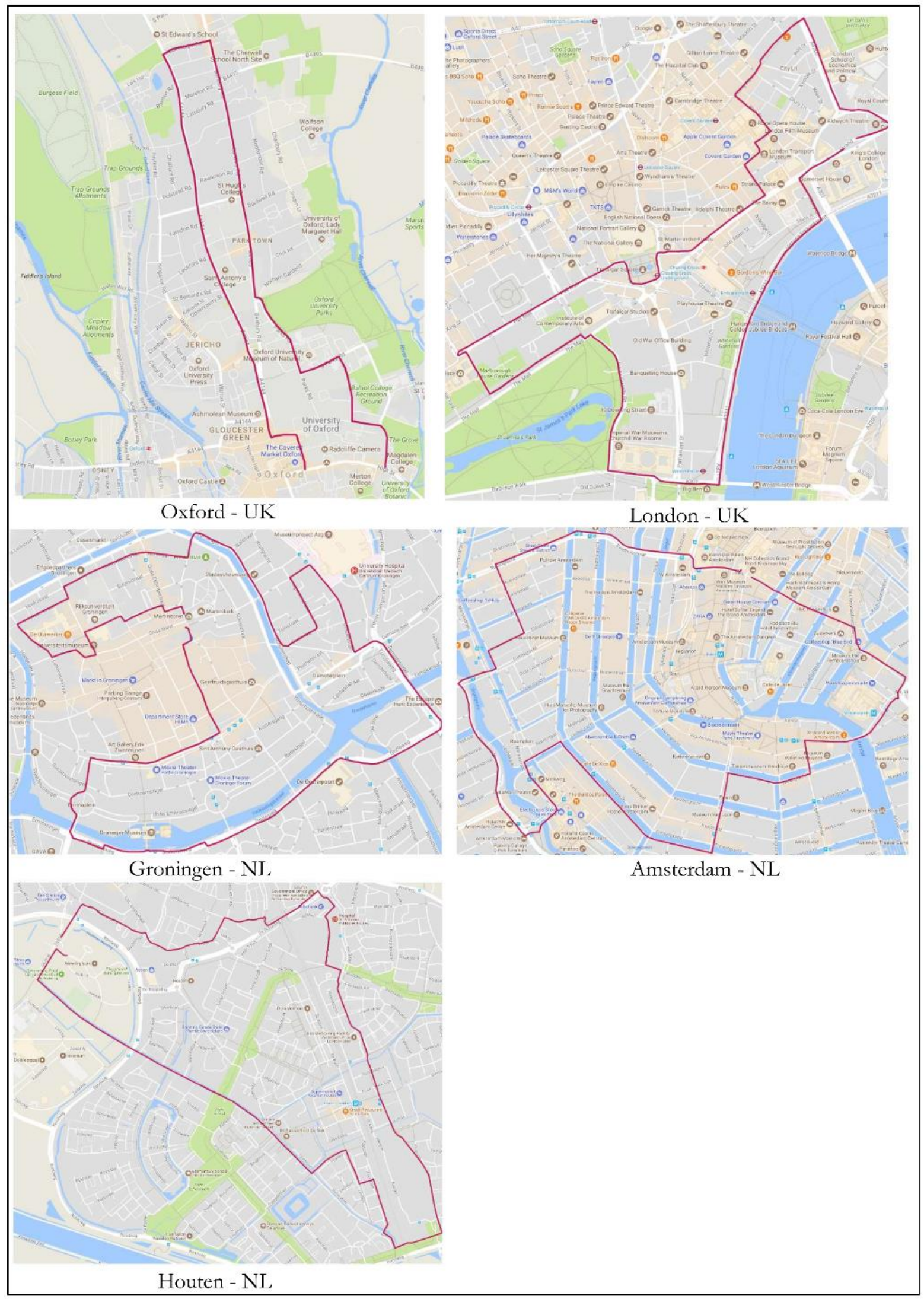

Figure 1- Routes selected for data collection. 


\subsection{Measurements}

After selecting the route and participants, during the experimental procedures, we assessed the following variables: stress level, noise level and environmental characteristics. After the data were collected, they were georeferenced and collated into a single database. The temporal resolution adopted for the analysis was one observation per second.

\subsection{Stress biomarker}

To assess the stress levels, we used an experimental Smartband. This Smartband collects skin conductivity and skin temperature data at a sampling rate of $10 \mathrm{~Hz}$ and has already been used in other studies with cyclists (Nuñez et al., 2018; Zeile et al., 2016). Electrodermal response activity, based on galvanic skin response, measures changes in the conductivity and temperature of the skin and monitors responses to certain physiological emotions (Caviedes et al., 2017).

In normal exercise, both skin conductivity and temperature increase gradually. During a stressful event, the skin conductivity increases suddenly while the skin temperature decreases rapidly (Kreibig, 2010; Nuñez et al., 2018; Rodrigues da Silva et al., 2014). Skin conductance increases by the difference between sweat production and absorption by the skin, while skin temperature decreases because the cutaneous blood goes to the active muscles, helping individuals to be prepared to escape or fight against the stressor, if necessary. We present a detailed description of the steps for processing and classifying the stress in the technical appendix.

\subsection{Noise level}

Noise level data were collected using a mobile measurement strategy. To do this, a sensor developed at Ghent University (Dekoninck et al., 2013) was used. This device was designed and adjusted to record noise data while the participants are riding a bicycle and geographical coordinates are tagged. The noise sensor was put inside a backpack, but the microphone was adapted on the backpack shoulder straps, which was closer to the participant's ear, preventing an acoustic shadow. To analyze the noise level data, we used the $\mathrm{L}_{\mathrm{Aeq}, 1 \mathrm{sec}}$, the $\mathrm{A}$ weighted equivalent sound level, which was calculated second by second and then geocoded along the route.

At the level of street segments, noise levels measured as LAeq,1sec will be higher on average when the amount of traffic is higher and traffic speed is higher. The dependence on vehicle speed depends on the fleet composition, the road surface and the speed. For light vehicles at higher speeds, rolling noise will be dominant and $\mathrm{a} \log (\mathrm{v})$ dependence is expected, while for heavy vehicles and lower speed, the noise level in $\mathrm{dB}$ will depend linearly on vehicle speed, v. So overall, on a segment with more vehicles at higher speed, the distribution of LAeq,1 sec will tend to higher values. 


\subsection{Environmental characteristics}

Although each city presented different characteristics along the routes, we created a classification based on six groups: Street hierarchy (Primary street; Secondary street; Tertiary street), Street direction (Two-way; Oneway; One-way contra-flow), Surface (Asphalt; Cobbles; Concrete pavers; Off-road), Type of road (General use; Shared-use sidewalk/mixed-use sidewalk; Shared-use bus lane; Cycle path [with a physical segregation]; Cycle lane [without a physical segregation]), Intersection (Straight; Turn same side [NL = right; UK = left]; Turn opposite side $[\mathrm{NL}=$ left; $\mathrm{UK}=$ right]), Roadworks (with; without). In each group, the categories were organized from the best scenario (reference category) to the worst scenario for cycling (Figure 2). It is important to highlight that, along the standard route, while cycling, the participant was exposed to different combinations of environmental characteristics. The percentages of environment attributes distributed along the routes in each city and in total are presented in Table 1.

Table 1 - The distribution of environment attributes (in \%) along the routes in each city and in total.

\begin{tabular}{|c|c|c|c|c|c|c|}
\hline & Houten & Oxford & Groningen & Amsterdam & London & Total \\
\hline \multicolumn{7}{|l|}{ Type of road } \\
\hline General use & 24.4 & 34.1 & 41.6 & 49.9 & 59.2 & 42.4 \\
\hline Bus shared & $\varnothing$ & 21.6 & $\varnothing$ & $\varnothing$ & 7.1 & 5.9 \\
\hline Sidewalk shared & $\varnothing$ & $\varnothing$ & 0.7 & $\varnothing$ & 2.4 & 0.7 \\
\hline Cyclelane & 8.6 & 28.7 & 17.7 & 17.8 & 6.4 & 15.5 \\
\hline Cyclepath & 66.9 & 15.6 & 39.9 & 32.3 & 25.0 & 35.5 \\
\hline \multicolumn{7}{|l|}{ Road hierarchy } \\
\hline Tertiary road & 94.6 & 27.9 & 49.3 & 60.6 & 20.5 & 48.5 \\
\hline Secondary & 5.4 & 19.9 & 15.8 & 15.7 & 36.2 & 19.4 \\
\hline Primary & $\varnothing$ & 52.2 & 34.9 & 23.8 & 43.3 & 32.0 \\
\hline \multicolumn{7}{|l|}{ Intersection } \\
\hline Straight & 96.1 & 94.1 & 88.5 & 84.9 & 88.1 & 90.4 \\
\hline Turn same side & 1.2 & 1.5 & 3.5 & 3.4 & 0.7 & 2.0 \\
\hline Turn opposite side & 2.7 & 4.4 & 8.0 & 11.7 & 11.3 & 7.7 \\
\hline \multicolumn{7}{|l|}{ Surface } \\
\hline Asphalt & 82.7 & 95.0 & 69.0 & 48.4 & 97.5 & 80.2 \\
\hline Concrete pavers & 17.3 & 3.2 & 25.2 & 38.5 & $\varnothing$ & 15.6 \\
\hline Cobblestones & $\varnothing$ & 0.7 & 5.7 & 13.1 & 2.5 & 4.0 \\
\hline Off-road & $\varnothing$ & 1.1 & $\varnothing$ & $\varnothing$ & $\varnothing$ & 0.2 \\
\hline \multicolumn{7}{|l|}{ Street direction } \\
\hline One-way & 70.9 & 8.9 & 18.2 & 44.1 & 75.4 & 43.7 \\
\hline Two-way & 29.1 & 91.1 & 75.8 & 53.8 & 23.3 & 54.3 \\
\hline $\begin{array}{r}\text { One-way (reverse for } \\
\text { cyclists) }\end{array}$ & $\varnothing$ & 0.0 & 6.0 & 2.1 & 1.3 & 2.0 \\
\hline \multicolumn{7}{|l|}{ Roadworks } \\
\hline Normal & 100.0 & 99.3 & 99.5 & 100.0 & 98.7 & 99.5 \\
\hline Roadworks & $\varnothing$ & 0.7 & 0.5 & $\varnothing$ & 1.3 & 0.6 \\
\hline
\end{tabular}

$\varnothing=$ no observations; 

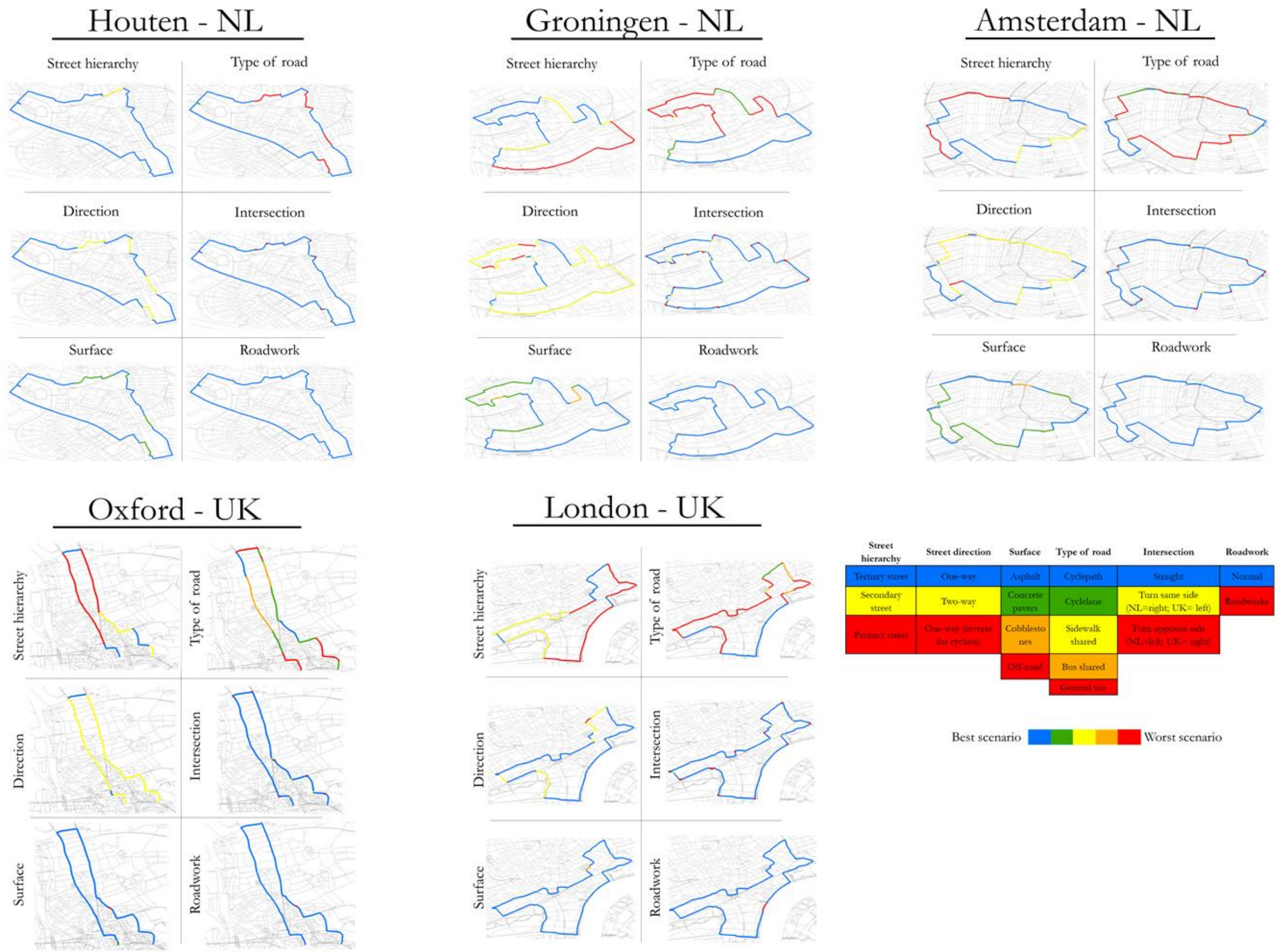

Figure 2 - Summary of environment classification group and their categories varying from the worst to the best scenario for the cyclists. 


\subsection{Procedures for data collection}

Data collection took place on weekdays from 10th May to 20th July 2018, from 7am to 6pm. The participants were first familiarized with the GPS navigation device, and they rode around the block so as to become familiar with the navigation task. They were then equipped with the sensors and instructed on how the test phase would be carried out. Thereafter, using a bike, participants completed the standard route, at a comfortable speed, and all measurements were collected continuously by the environmental and physiological sensors. The participants were advised to ride safely, respecting the traffic laws and using the cycling infrastructures whenever they were available.

\subsection{Video demonstration of experimental process and cities' environments.}

We recommend that readers watch the five video recordings containing one participant per city to obtain a more practical understanding of the process and the cities' environments. The videos can be found here: https://drive.google.com/drive/folders/1rj SnqDxpzIVEofvH71goZGH0bSaPHnw?usp=sharing.

\subsection{Data analysis}

After acquiring the data, all records (70 individuals and 1,144,099 observations during bicycle rides) were synchronized, arranged chronologically and a Geographic Information System (GIS) was used to link the information related to the participants and the environment.

The relationship between street characteristics and stress was assessed by multilevel logistic regression analysis, with observations during bicycle rides (level 1) nested within participants (level 2). Level 1 consisted of the variables: type of road, street hierarchy, street direction, intersection, surface, roadwork and noise, assessed second-by-second along the trip. Aiming to control for the effects of possible mental and physical fatigue during the ride, we also added the variable 'time elapsed from the start (in seconds)' to all models. For Level 2, the variables were: age, gender and bike use frequency. Bike use frequency was used as an indicator of the participant's experience and was classified into three categories: five or fewer times per week; from six to ten times per week; more than ten times per week. Noise and age were used in a continuous form and, the dependent variable was categorized dichotomously into stressful event or normal condition.

The number of cities was too small $(\mathrm{n}=5)$ for a three-level structure with events nested within individuals and nested within cities. Instead, a series of dummy indicators for the various cities was created and added to the two-level model (making cities another individual-specific characteristic). In addition to this global model, we created five independent models for each city, following the same two-level structure. Odds ratios (OR) and their 95\% confidence intervals are reported, as well as the $p$-values, random-effects parameters, intra-class correlation coefficients (ICCs) and Wald chi $^{2}$ statistics. To measure the goodness of fit for the models, we adopted three different methods: 1) McFadden's rho-squared at constant, calculated by the following equation: 
1 - (log likelihood for final model/log likelihood for a model containing only a constant); 2) McFadden's rhosquared at zero where the denominator is not the log-likelihood at the constant but the log-likelihood at zero, which is: $L L=-n \times L N(2)$, where $n$ is the number of observations and 3) C-statistic, which is equivalent to the area under the receiver operating characteristic (ROC) curve, and is a measure used for summarizing the discriminatory ability of a binary prediction model (Hosmer and Lemeshow, 2000). As a general rule, if $\mathrm{ROC}=0.5$, this suggests no discrimination; if $0.7 \leq \mathrm{ROC}<0.8$, this is considered acceptable discrimination; if $0.8 \leq \mathrm{ROC}<0.9$, is considered excellent discrimination; and if ROC $\geq 0.9$, this is considered outstanding discrimination (ibid).

\subsection{Limitations of the research}

Aiming to avoid the exposure of vulnerable people to risks during the experiment, our selection criteria were very restrictive, resulting in a sample consisting mainly of young adults, males and those with a higher education level. Because of this, the sample becomes more homogeneous, but the risk of having a type I statistical error is lower as this population group could be less affected by stress factors.

Another limitation is related to the cross-sectional study design. The results of this research indicate that there is a significant association between stress and cycling infrastructures but it is not possible to define if the stress levels were indeed higher before the infrastructures were implemented. However, it is important to highlight that this study design allowed the same individual to be exposed to different conditions along the route. In addition, this does not need to be a limitation when the interest is in comparing routes or cities

It is also important note that there are other relevant variables that could affect the cyclists' stress, which were not considered in this study. Teixeira et al. (2019) developed a model with 39 possible variables that could be related to stress in a bicycle commuting context. Those variables were grouped into eight clusters: personal characteristics, urban environment, traffic characteristics, natural environment, social environment, temporal information, cyclists' characteristics and trip characteristics. Some of those variables will be addressed in a future study analyzing the videos recorded, but some others, such as air pollution, temperature and vibration, cannot be considered with the data at hand. In addition, there are three other possible stressors inherent to our method: attention to GPS for navigation, physical activity, and being followed by the researcher who was recording the video. We assume that these last three variables could be potential confounding factors, as each participant may respond differently to each of them, but they were essential to developing the research.

Finally, the duration of the real-world experiment may impact the accuracy of the stress identification. Kyriakou et al (2019) found an attenuation along a lab study, which could be also the case for a real-world experiment. However, we believe that the reason for the lab accuracy attenuation is due to the repeated nature of the lab stimuli (horn), which definitely is not the case of the real-world bicycle ride. Although we can only speculate about it, our results show that each additional second increased significantly the likelihood of a stress event by a 
factor of 1.000015. That means that, IF there is an attenuation, it is being compensated by another factor, such as physical and/or mental fatigue (see the temporal effect section at Table 3).

\section{Results and Discussion}

\subsection{Descriptive statistics}

The final sample consisted of 70 participants as follows: 14 participants in Oxford; 14 in London; 16 in Houten; 15 in Groningen and 11 in Amsterdam. The demographic characteristics of the sample are presented in Table 2. In general, the sample mainly comprised males $(61.43 \%)$, people aged 25 or over $(68.57 \%)$, with a higher education level, living with a partner or other adults, working full-time and including 18 different nationalities.

On average, the participants took 27.2 minutes to ride the standard route whereby the participants were classified as under stress for $8.8 \%$ of the time. This value varied among the cities as shown in Figure 3 (the average values per city are marked as " $\mathrm{x}$ ").

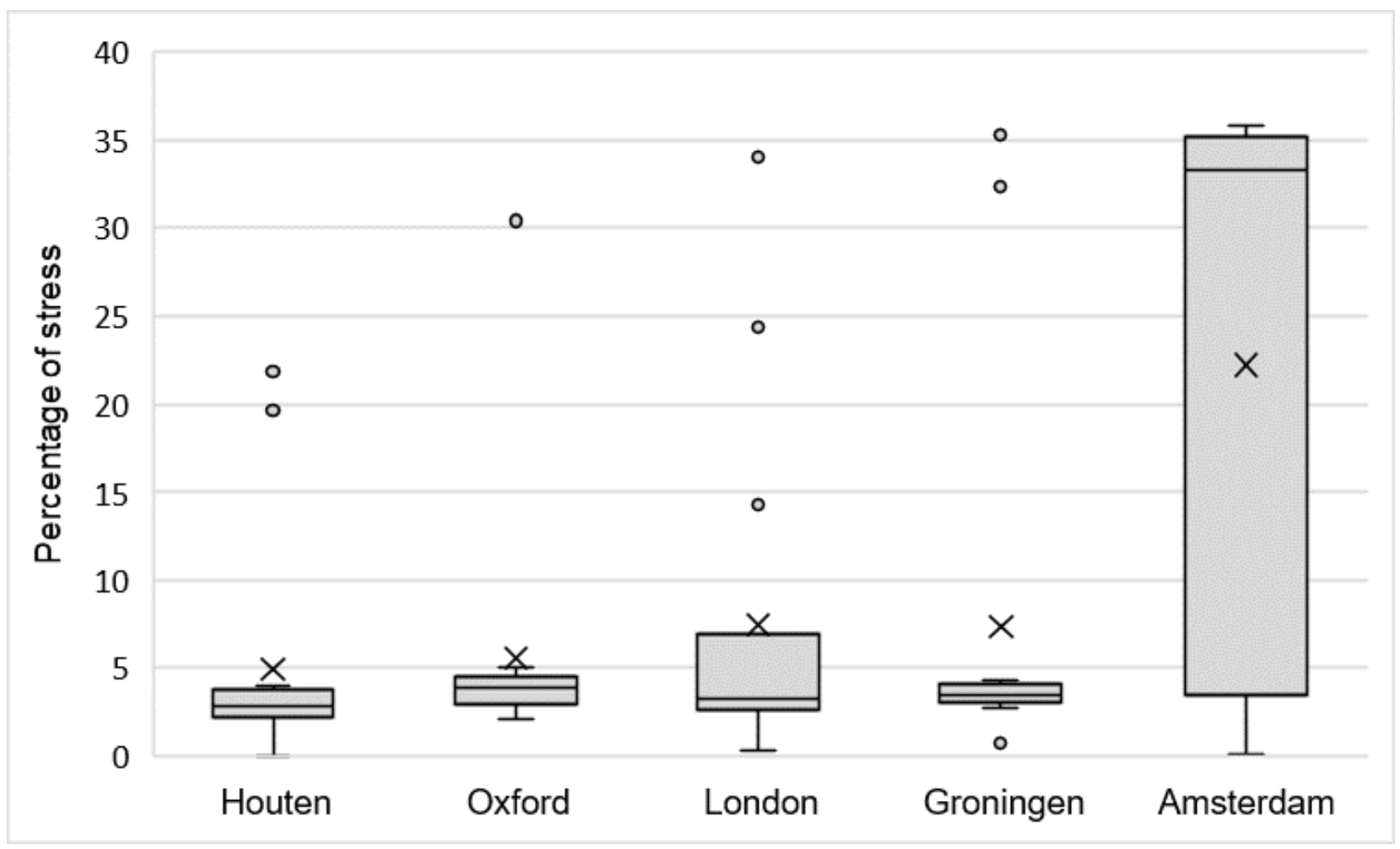

Figure 3 - Distribution of stress, grouped by cities ( $\mathrm{n}=70$ participants)

\subsection{Environmental characteristics and stress}

The results from the multilevel logistic regression for all 70 participants are presented in Table 3. Below, we present the results and discussion separated into sections related to the groups of variables. 
Table 2- Sample characteristics, overall and stratified by city $(n=70)$.

\begin{tabular}{|c|c|c|c|c|c|c|c|c|c|c|c|c|}
\hline & \multicolumn{2}{|c|}{ General } & \multicolumn{2}{|c|}{ Houten } & \multicolumn{2}{|c|}{ Oxford } & \multicolumn{2}{|c|}{ Groningen } & \multicolumn{2}{|c|}{ Amsterdam } & \multicolumn{2}{|c|}{ London } \\
\hline & $\mathrm{n}$ & $\%$ & $\mathrm{n}$ & $\%$ & $n$ & $\%$ & $n$ & $\%$ & $n$ & $\%$ & $\mathrm{n}$ & $\%$ \\
\hline \multicolumn{13}{|l|}{ Sex } \\
\hline Female & 27 & 38.57 & 7 & 43.75 & 5 & 35.71 & 6 & 40 & 4 & 36.36 & 5 & 35.71 \\
\hline Male & 43 & 61.43 & 9 & 56.25 & 9 & 64.29 & 9 & 60 & 7 & 63.64 & 9 & 64.29 \\
\hline \multicolumn{13}{|l|}{ Nationality } \\
\hline Dutch & 19 & 27.14 & & & & & & & & & & \\
\hline Brazilian & 18 & 25.71 & & & & & & & & & & \\
\hline British & 11 & 15.71 & & & & & & & & & & \\
\hline Italian & 5 & 7.14 & & & & & & & & & & \\
\hline French & 2 & 2.86 & & & & & & & & & & \\
\hline German & 2 & 2.86 & & & & & & & & & & \\
\hline American & 2 & 2.86 & & & & & & & & & & \\
\hline other & 11 & 15.71 & & & & & & & & & & \\
\hline \multicolumn{13}{|l|}{ Age (year bands) } \\
\hline 18 to 24 years & 22 & 31.43 & 3 & 18.75 & 6 & 42.86 & 8 & 53.33 & 2 & 18.18 & 3 & 21.43 \\
\hline 25 to 30 years & 48 & 68.57 & 13 & 81.25 & 8 & 57.14 & 7 & 46.67 & 9 & 81.82 & 11 & 78.57 \\
\hline \multicolumn{13}{|l|}{ Education } \\
\hline Primary or Secondary & 4 & 5.71 & & & 2 & 14.29 & 1 & 6.67 & 1 & 9.09 & & \\
\hline Undergraduate & 13 & 18.57 & & & 4 & 28.57 & 4 & 26.67 & 2 & 18.18 & 3 & 21.43 \\
\hline Graduate or equivalent & 22 & 31.43 & 6 & 37.5 & 3 & 21.43 & 4 & 26.67 & 4 & 36.36 & 5 & 35.71 \\
\hline Postgraduate or equivalent & 31 & 44.29 & 10 & 62.5 & 5 & 35.71 & 6 & 40 & 4 & 36.36 & 6 & 42.86 \\
\hline \multicolumn{13}{|l|}{ Marital status } \\
\hline Single & 29 & 41.43 & 1 & 6.25 & 7 & 50 & 9 & 60 & 8 & 72.73 & 4 & 28.57 \\
\hline Partnered & 41 & 58.57 & 15 & 93.75 & 7 & 50 & 6 & 40 & 3 & 27.27 & 10 & 71.43 \\
\hline \multicolumn{13}{|l|}{ Household composition } \\
\hline Living with partner only & 23 & 32.86 & 10 & 62.5 & 1 & 7.14 & 6 & 40 & 2 & 18.18 & 4 & 28.57 \\
\hline Living with adults other than partner or parent(s) & 19 & 27.14 & & & 8 & 57.14 & 3 & 20 & & & 8 & 57.14 \\
\hline Living alone & 12 & 17.14 & 1 & 6.25 & 2 & 14.29 & 3 & 20 & 6 & 54.55 & & \\
\hline Living with partner and child(ren) only & 6 & 8.57 & 5 & 31.25 & & & & & 1 & 9.09 & & \\
\hline Living with parent(s) only & 5 & 7.14 & & & 2 & 14.29 & 3 & 20 & & & & \\
\hline Living with child(ren) only & 1 & 1.43 & & & 1 & 7.14 & & & & & & \\
\hline other & 4 & 5.71 & & & & & & & 2 & 18.18 & 2 & 14.29 \\
\hline \multicolumn{13}{|l|}{ Employment status } \\
\hline Working fulltime & 43 & 61.43 & 12 & 75 & 8 & 57.14 & 6 & 40 & 5 & 45.45 & 12 & 85.71 \\
\hline Working part time & 11 & 15.71 & 4 & 25 & 2 & 14.29 & 2 & 13.33 & 2 & 18.18 & 1 & 7.14 \\
\hline Student & 11 & 15.71 & & & 3 & 21.43 & 6 & 40 & 1 & 9.09 & 1 & 7.14 \\
\hline Not working, looking for a job & 1 & 1.43 & & & & & & & 1 & 9.09 & & \\
\hline Not working, not looking for a job & 2 & 2.86 & & & 1 & 7.14 & 1 & 6.67 & & & & \\
\hline other & 2 & 2.86 & & & & & & & 2 & 18.18 & & \\
\hline
\end{tabular}


Table 3 - Multilevel logistic regression analyses nested within all participants ( $n=70)$.

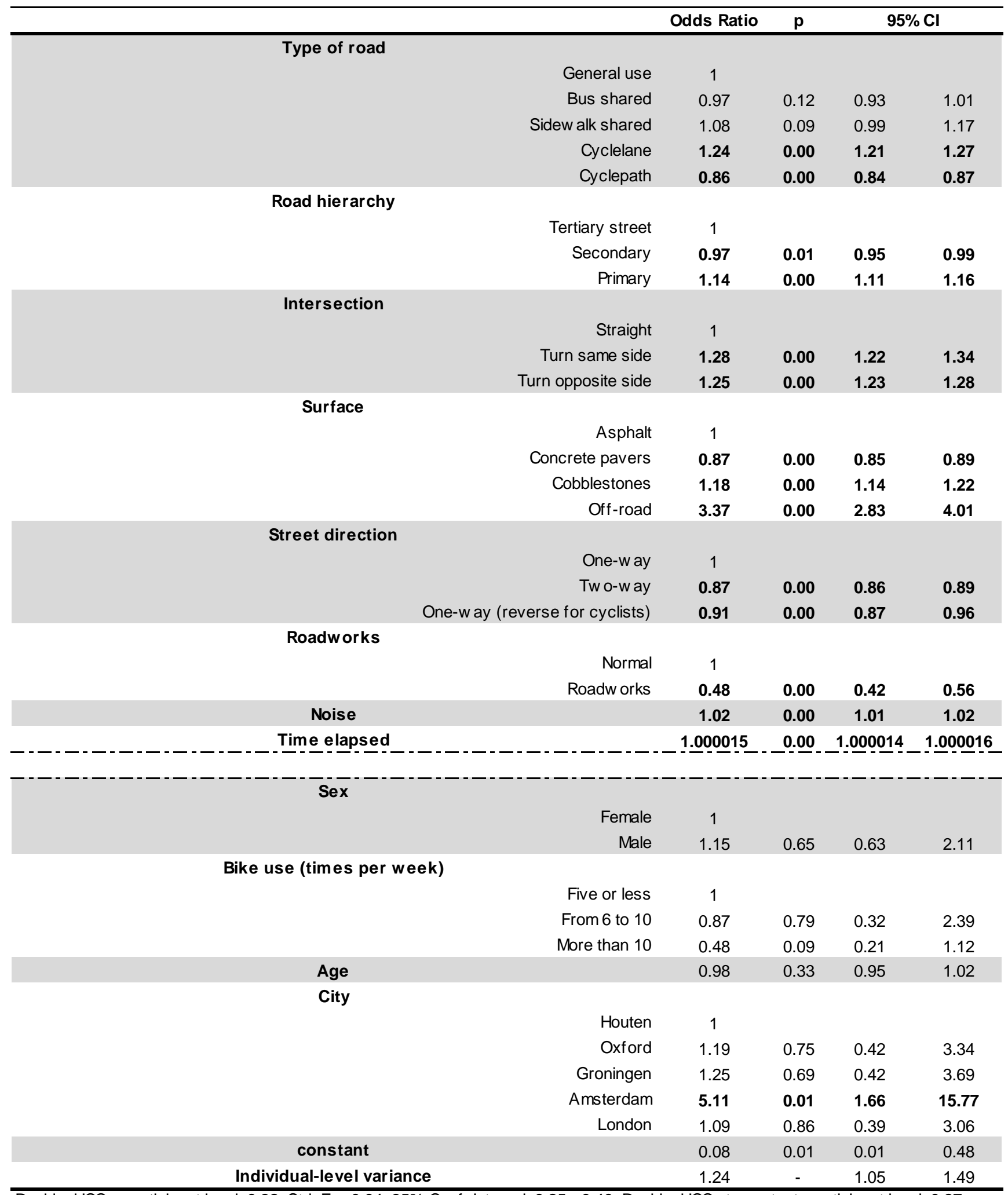

Residual ICC - participant level: 0.32; Std. Err.:0.04; 95\% Conf. Interval: 0.25 - 0.40; Residual ICC at constant- participant level: 0.37; Std. Err.:0.04; 95\% Conf. Interval: 0.30 - 0.46

Nobs=1,144,099; Wald Chi-square $=95093.21, p<0.001 ;$ McFadden rho-square at constant: 0.004; McFadden rho-square at zero: 0.649 C-Statistic - ROC area: 0.8142; Std Err. 0.001; 95\% Conf. Interval: 0.81277 - 0.8156 


\section{Type of road}

Related to the type of road, we found that physical segregation in the form of a cycle path reduced the odds by 14 percentage points when compared to the reference category of riding on a general use street $(\mathrm{OR}=0.86$ CI95\% = 0.84-0.87). The probability of stress was significantly higher when the cyclists were riding on a cycle lane $(\mathrm{OR}=1.24 \mathrm{CI} 95 \%=1.21-1.27)$ when compared to riding on a general use street.

The findings are consistent with the notion that physical separation of cyclists prevents stress. This result is plausible given that physical separation means that less attention to cycle safety is demanded from cyclists, allowing them to 'relax' until the next intersection. By contrast, riding on cycle lanes without segregation requires constant attention (Pucher and Buehler, 2012). Thus, several studies point out a preference for cycle paths with physical segregation instead of cycle lanes or shared traffic (Abraham et al., 2002; Hunt and Abraham, 2007; Stinson and Bhat, 2003; Wardman et al., 2007). Maybe this preference reflects that riding on these specific lanes tend to be safer to riding on a general use street, thus leading to lower cycling injury risk (Reynolds et al., 2009; Thomas et al., 2013) and would, therefore, reduce stress as well. In addition, previous studies found that cyclists' levels of comfort are inversely associated with the proximity to motorized traffic (Chuang et al., 2013; Kim et al., 2007) and separated bike paths are preferred by users (Garder et al., 1998; Sener et al., 2009; Winters et al., 2011).

One unexpected result was the greater odds ratio for stress when the cyclists were riding on a cycle lane when compared to riding on a general use street. Considering that cycle lanes and cycle paths are created based not only on the cyclists' demand but also considering street characteristics such as speed and flow, in general, they tend to be built where the risk for cyclists is higher (EU's Intelligent Energy., 2010). Hence, although we found a higher risk of having a stressful event on cycle lanes when compared to shared streets, it is possible that, before building them, those streets were even more stressful. Considering that and the fact that the criteria to build cycle paths with physical segregation (instead of cycle lanes) usually demand streets with even more automobile flow and higher speed limits, the expectation would be to find more stress.

\section{Road hierarchy}

Riding on a primary road presented a probability of stress that is 14 percentage points higher than when riding on a tertiary street (Table 3). Considering that primary roads tend to present high levels of automobile flow and speed (Gattis and Watts, 1999), and they are more hazardous than secondary or tertiary roads (Reynolds et al., 2009), it is plausible that the level of attention and stress increase on these roads.

\section{Surface}

Still related to road characteristics, our results support the idea that the kind of surface is associated with stress as well. While riding on concrete pavers reduced the probability of stress, riding on cobbled or off-road streets 
increased the likelihood of a stressful event by, respectively, 18 and 237 percentage points compared to riding on asphalt. Pavement smoothness is important to bicycle control and comfort, significantly affecting bicycle rideability (American Association of and State Highway and Transportation Officials, 2012). In addition, even small cobblestones could have a high impact related to vibration (Olieman et al., 2012). On the other hand, concrete pavers produce less vibration than cobbles for cyclists but, for car drivers, they could be effective in reducing the speed, aiming at reducing the vibration and sound resulting from tire-road interaction. Based on these facts and our results, considering concrete pavers, the traffic calming effect may surpass the lack of smoothness for cyclists in reducing stress levels.

\section{Intersection}

Our results have shown a higher likelihood of having a stressful event when cyclists need to turn into a street (which is not necessarily a problem, given that the cyclist needs to be prepared to deal with a new situation). We found that when turning to the same side of the road [NL = right; $\mathrm{UK}=$ left], the probability of stress was 28 percentage points higher than when going straight ahead, while when turning to the opposite side of the road $[\mathrm{NL}=$ left; $\mathrm{UK}=$ right $]$ the probability was 25 percentage points higher (Table 3). Thus, several studies have investigated the relationship between motor-vehicles and bicycles in crash frequency at intersections (Brüde and Larsson, 1993; Miranda-Moreno et al., 2011; Wang and Nihan, 2004). Intersections are complex zones where many interactions can occur among cyclists, motor-vehicles and pedestrians (Strauss et al., 2013) and where a considerable proportion of cyclist injuries happens (Aldred et al., 2018; Strauss et al., 2013; Williams, 2015). Additionally, Broach et al. (2012) suggest that cyclists are sensitive to the frequency of turns, as they likely delay cyclists, and also add a mental demand on cycling. A study by Summala et al. (1996) illustrated that car drivers turning right scan the right leg of the T-intersection less frequently and later than those turning left. Therefore, it appears that drivers adopt different visual scanning strategies concentrating on detecting more frequent and major dangers but overlooking and even masking visual information on less frequent dangers (as a cyclist, for example).

\section{Street direction}

Related with the street direction, our results support the idea that riding on a two-way or one-way contra-flow is less stressful for the cyclist when compared with the traditional one-way, reducing the likelihood of a stress event by 13 and 9 percentage points, respectively (Table 3). Some authors specifically recommend that cycle lanes and cycle paths should be one-way, carrying traffic in the same direction as adjacent motor vehicle traffic (Litman et al., 2009). A reason for that is that two-way facilities represent an additional risk for cyclists (Methorst et al., 2017; Schepers et al., 2017). However, when considering the streets in general, two-way or contra-flow could be highly attractive for cyclists because it creates shortcuts. Moreover, contra-flow has proven to be safe, even in the narrowest streets (EU's Intelligent Energy., 2010). Additionally, when cycling in the same direction 
as automobiles, only the motorist makes such judgments, and the cyclist cannot see or predict what the car coming from behind will do (EU's Intelligent Energy., 2010).

\section{Noise}

In our study, high noise levels were associated with higher probabilities of having a stressful event while cycling (Table 3). Each additional LAeq,1 sec value increased significantly the likelihood for a stress event by a factor of 1.02. This confirms the results found by Nuñez et al. (2018). Being away from traffic noise is considered an important motivator for cycling (Winters et al., 2011). The pleasantness of following a path through the city has been associated with the sonic and visual environment (Aumond et al., 2017) and salient sounds were found to trigger attention and cause changes in reported pleasantness of the environment (Filipan et al., 2019). Finally, sounds may disturb cyclists' level of concentration (Suetomi and Niibe, 2002).

\section{Roadworks}

The last environmental variable associated with stress was roadworks, i.e., in those places, the odds ratio for a stressful event was 52 percentage points lower when compared with places without roadworks. It is important to highlight that there are some recommendations to avoid blocking or hindering pedestrian and cyclist flows while roads have roadworks. For example, the Construction Guidance Document for Contractors, produced by Transport for London, emphasized ten potential hazards or impacts that must be considered when designing "cyclist-friendly" temporary traffic management (Barratt, 2014). As can be seen in Figure 4, in the case of London and Groningen the roadworks included a physical barrier separating the cyclists from the vehicles, which was not there before the roadworks. We hypothesize that, as the results for cycle paths indicate, segregation could promote more safety and reduce the odds of stress events occurring. On the other hand, in the case of Oxford, although there was also segregation from the traffic, the segment with roadworks forced cyclists to share the space with pedestrians (as a shared sidewalk) on a poor surface. Perhaps, because of that, for London and Groningen we noted lower risks for a stressful event while for Oxford those places presented additional risks (Figure 4).

\section{Temporal effect}

The main reason for adding this variable to the model was to control a possible physical and/or mental fatigue. Our results show that each additional second riding the bicycle significantly increased the likelihood of a stress event by a factor of 1.000015. Although it seems a very small effect, if we consider that, on average, the participants took 27.2 minutes (1632 seconds) to travel the standard route, this means a 2.4 percentage points increase in the chances of a stress event comparing the first and the last second. In addition, when we added this variable to all our model, we verified a significant improvement of their fits, as shown by the changes in the Chisquare statistic. 


\section{Personal characteristics and city}

Personal characteristics such as gender, age and bike use frequency were not associated with stressful events when the participants were cycling. Considering the context of cities, the distribution of stress data is similar until the median for all cities except Amsterdam (as shown in Figure 3). The odds ratio - the odds of stress over the odds of non-stress - for Amsterdam is almost 5 times as large as in the reference city, Houten. Although Amsterdam is known as “the bicycle capital of the world” (Zee, 2015), the words of Anna Luten, Amsterdam's first bicycle mayor, help us understand why the results for Amsterdam are so different : "Some parts of the city are just too busy - there are too many bikes, too many scooters, too many cars, too many pedestrians. There's no space. It is a big source of conflict" (Van Mead, 2016, no pagination). This opinion is based on the facts that there are 1 million bikes for a population of 1.1 million, and $68 \%$ of bike journeys are made in the city center, which has just $11 \%$ of infrastructure, frequently causing bike jams and forcing cyclists to stop at every junction. Additionally, Amsterdam receives around 18 million tourists a year who are unfamiliar with the city's unwritten cycling rules (ibid).
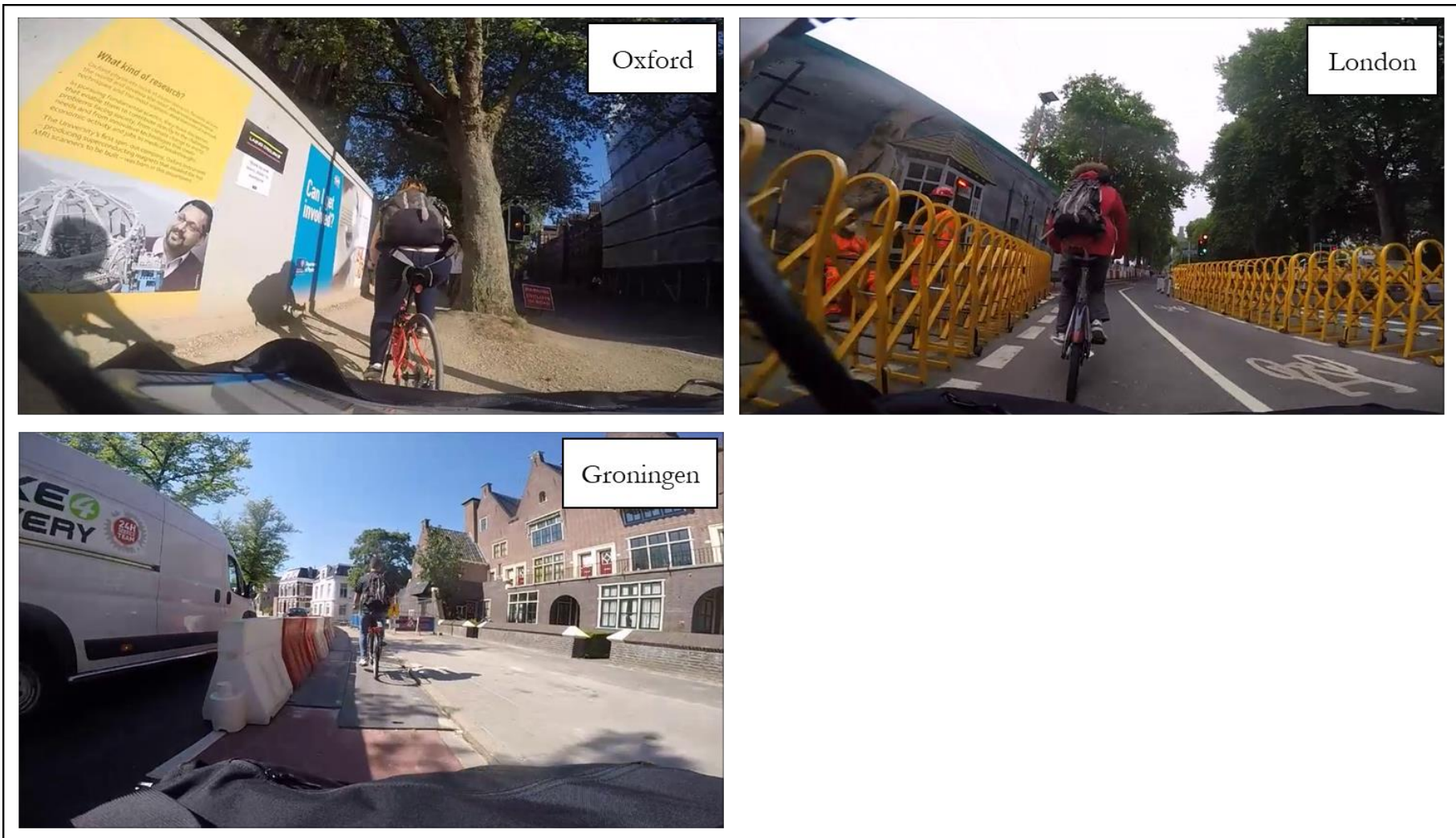

Figure 4- Segments with roadworks in Oxford, London and Groningen routes. 
Related to the model's fit indexes, the model presented a McFadden's rho-squared at constant equal to 0.004 and at zero equal to 0.649 . The difference in values is caused by the unequal distribution of 0 and 1 scores (because participants were only experiencing stress in $8.8 \%$ of the observations) and indicate that it is very difficult for independent variables beyond the constant to 'beat' the explanatory power offered by that constant. Like the McFadden's rho-squares at zero, the C-statistic suggests that the total model fits the data well. A value of 0.81 for the area under the ROC curve, which is considered an excellent discrimination. Below we discuss the effects of the main independent variables of interest one by one.

\section{Exploring a model with interactions}

Aiming to test a possible interaction between road hierarchies and road types, we have performed the same model presented in Table 3, but combining those two variables. In this way, the following 12 categories were created: General Primary (reference category); General Secondary; General Tertiary; Bus shared Primary; Sidewalk shared Primary; Sidewalk shared Tertiary; Cycle Lane Primary; Cycle Lane Secondary; Cycle Lane Tertiary; Cycle Path Primary; Cycle Path Secondary; Cycle path Tertiary. The results indicate that for all the categories involving the cycle paths the likelihoods for a stressful event were significantly smaller when compared to general primary roads. But, for the cycle lanes, only when riding on tertiary streets we found higher probabilities of having a stressful event when compared with general tertiary streets $\left(\mathrm{OR}=1.19 ; \mathrm{CI}_{95 \%}=1.15\right.$ 1.23). When riding on a cycle lane in a secondary or primary road, we did not find significant differences when compared to riding on general primary roads $\left(\mathrm{OR}=0.99 ; \mathrm{CI}_{95 \%}=0.95-1.04\right.$ and $\mathrm{OR}=0.97 ; \mathrm{CI}_{95 \%}=0.93-1.005$, respectively). We also found interesting results for the general roads. Differently from the model presented in Table 3, for general use context, both secondary and tertiary stress presented smaller likelihoods for a stressful event when compared to general primary roads $\left(\mathrm{OR}=0.88 ; \mathrm{CI}_{95 \%}=0.86-0.90\right.$ and $\mathrm{OR}=0.85 ; \mathrm{CI}_{95 \%}=0.83$ 0.88 , respectively).

\subsection{Models for individual cities}

Although the probability for a stressful event was not statistically different among Oxford, Groningen, London and Houten in the overall model (Table 3), several differences between these cities become evident when separate models are estimated for each (Table 4). Overall, only intersections presented consistent results across the individual city models. Thus, there is robust evidence that, at intersection points, turning left or right increases the risk of having a stressful event when compared to going straight ahead. Noise is shown to be a fairly consistent stressor, although there is an inverse relationship between stress and noise for Groningen. Furthermore, with respect to cycling infrastructure, we found a larger likelihood for a stress event while riding on a cycle lane (without physical segregation) when compared to riding on a general use street in four out of the five cities (Table 4). 
On the other hand, the cycle paths with physical segregation between cyclists and drivers presented a smaller likelihood for a stressful event in three out of the five cities (Oxford, London and Amsterdam). For those cities, the odds ratios were 20 to 28 percentage points lower (Table 4). For Houten, we did not find a significant association and in Groningen, riding on cycle paths was a risk factor for a stressful event $(\mathrm{OR}=1.61$ $\mathrm{CI} 95 \%=1.41-1.82)$. For the other variables and categories, the results varied between the different cities without an established standard.

It is important to highlight that Groningen presented three interesting results going against the grain of the other cities. Cycling on Groningen cycle paths represented additional risks for stressful events while in the other cities these cycling infrastructures presented smaller likelihoods. In contrast, while all the other cities presented higher risks for noise, Groningen presented lower risks of having a stressful event. For now, we do not have enough elements to explain these counterintuitive results, although a future qualitative analysis, using the recorded videos, could explain them.

The substantial differences among the studied cities could be influenced by the specific differences in environmental characteristics, such as the example of the roadworks in London, Groningen and Oxford. On the other hand, the local culture can also moderate the effect of the environmental characteristics, i.e., the same infrastructure provision, program, or policy can have different relationships with cycling depending on the context (Aldred and Jungnickel, 2014). These contexts could vary from a macro to micro level. For example, there are substantial national differences concerning what cycling means in the UK and the Netherlands. Cycling is strongly associated with the Dutch national identity, supporting its cycling practices. On the other hand, in the $\mathrm{UK}$, cycling is not as linked to the British national identity (macro level) as in the Netherlands. However, it can be observed in the UK that there are cities with an 'emerging' and 'established' cycling culture (micro levels). In addition, in places where there are more cyclists, better car driver behavior is normally seen as car drivers see more cyclists, and they are more likely to also cycle, and hence may give greater consideration to people who are riding a bike (Jacobsen et al., 2015).

The models for each city also presented low values of the McFadden's rho-squared at constant, varying from 0.0035 to 0.0199 . However, as for the model for all participants, the McFadden's rho-squared values at zero and the C-statistics all indicate a good fit. The model for Amsterdam offers the lowest fit, given that the rho-squared at zero is 0.3190 because of the higher share of stress observations (Figure 5). Nonetheless, a value of 0.3190 is still acceptable, especially in conjunction with a C-statistic of 0.7303. 
Table 4 - Summary of results from the city models.

\begin{tabular}{|c|c|c|c|c|c|c|c|c|c|c|c|c|c|c|c|c|c|c|c|c|c|}
\hline & \multicolumn{4}{|c|}{ Oxford } & \multicolumn{4}{|c|}{ London } & \multicolumn{4}{|c|}{ Houten } & \multicolumn{4}{|c|}{ Groningen } & \multicolumn{4}{|c|}{ Amsterdam } & \multirow{2}{*}{$\begin{array}{c}\begin{array}{c}\text { Sum mary - } \\
\text { all cities }\end{array} \\
\end{array}$} \\
\hline Type of road & OR & $p$ & \multicolumn{2}{|c|}{$95 \% \mathrm{Cl}$} & OR & $p$ & \multicolumn{2}{|c|}{$95 \% \mathrm{Cl}$} & I OR & $p$ & $95 \%$ & $6 \mathrm{Cl}$ & OR & $\mathrm{p}$ & $95 \%$ & $6 \mathrm{Cl}$ & I OR & $\mathrm{p}$ & & $\% \mathrm{Cl}$ & \\
\hline General use & 1 & & & & 1 & & & & 1 & & & & 1 & & & & 1 & & & & ref \\
\hline Bus shared & 1.14 & 0.00 & 1.05 & 1.25 & 0.60 & 0.00 & 0.56 & 0.64 & & & & & & & & & 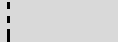 & & & & $\uparrow \downarrow \varnothing \varnothing \varnothing$ \\
\hline Sidew alk shared & & & & & 0.66 & 0.00 & 0.51 & 0.85 & 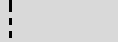 & & & & 2.16 & 0.00 & 1.82 & 2.56 & & & & & $\varnothing \downarrow \varnothing \uparrow \varnothing$ \\
\hline Cyclelane & 0.99 & 0.75 & 0.91 & 1.07 & 2.34 & 0.00 & 2.16 & 2.54 & 2.16 & 0.00 & 1.93 & 2.41 & 1.45 & 0.00 & 1.35 & $1.56 !$ & 1.21 & 0.00 & 1.17 & 1.26 & $-\uparrow \uparrow \uparrow \uparrow \uparrow$ \\
\hline Cyclepath & 0.80 & 0.00 & 0.73 & 0.88 & 0.73 & 0.00 & 0.70 & 0.77 & 1.08 & 0.11 & 0.98 & 1.20 & 1.61 & 0.00 & 1.41 & 1.82 & 0.72 & 0.00 & 0.69 & 0.75 & $\downarrow \downarrow-\uparrow \downarrow$ \\
\hline Road hierarchy & & & & & & & & & & & & & & & & & i & & & & \\
\hline Tertiary road & 1 & & & & 1 & & & & 1 & & & & 1 & & & & 1 & & & & ref \\
\hline Secondary & 0.96 & 0.39 & 0.86 & 1.06 & 0.81 & 0.00 & 0.77 & 0.86 & 0.75 & 0.00 & 0.67 & 0.84 & 0.94 & 0.18 & 0.85 & $1.03 i$ & 0.93 & 0.00 & 0.90 & 0.97 & $-\downarrow \downarrow-\downarrow$ \\
\hline Primary & 1.06 & 0.17 & 0.97 & 1.16 & 0.89 & 0.00 & 0.84 & 0.95 & $i$ & & & & 0.73 & 0.00 & 0.65 & 0.82 & 1.10 & 0.00 & 1.06 & 1.14 & $-\downarrow \varnothing \downarrow \uparrow$ \\
\hline Intersection & & & & & & & & & & & & & & & & & 1 & & & & \\
\hline Straight & 1 & & & & 1 & & & & 1 & & & & 1 & & & & 1 & & & & ref \\
\hline Turn same side & 1.20 & 0.03 & 1.02 & 1.41 & 2.40 & 0.00 & 1.99 & 2.88 & 1.39 & 0.00 & 1.16 & 1.66 & 1.39 & 0.00 & 1.27 & 1.52 & 1.28 & 0.00 & 1.20 & 1.37 & $\uparrow \uparrow \uparrow \uparrow \uparrow \uparrow$ \\
\hline Turn opposite side & 1.15 & 0.00 & 1.06 & 1.25 & 1.18 & 0.00 & 1.13 & 1.24 & 1.06 & 0.37 & 0.94 & 1.19 & 1.18 & 0.00 & 1.11 & 1.26 & 1.51 & 0.00 & 1.45 & 1.56 & $\uparrow \uparrow-\uparrow \uparrow$ \\
\hline Surface & & & & & & & & & & & & & & & & & ! & & & & \\
\hline Asphalt & 1 & & & & 1 & & & & 1 & & & & 1 & & & & 1 & & & & ref \\
\hline Concrete pavers & 0.94 & 0.30 & 0.84 & 1.06 & & & & & 1.10 & 0.07 & 0.99 & 1.21 & 0.80 & 0.00 & 0.75 & 0.85 & 0.84 & 0.00 & 0.81 & 0.86 & $-\varnothing-\downarrow \downarrow$ \\
\hline Cobblestones & 0.81 & 0.13 & 0.62 & 1.06 & 1.16 & 0.24 & 0.90 & 1.50 & 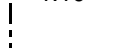 & & & & 0.82 & 0.00 & 0.76 & 0.90 & 1.29 & 0.00 & 1.24 & 1.35 & $--\varnothing \downarrow \downarrow$ \\
\hline Off-road & 0.52 & 0.01 & 0.33 & 0.82 & & & & & i & & & & i & & & & i & & & & $\downarrow \varnothing \varnothing \varnothing \varnothing$ \\
\hline Street direction & & & & & & & & & 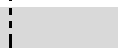 & & & & & & & & $i$ & & & & \\
\hline One-w ay & 1 & & & & 1 & & & & 1 & & & & 1 & & & & 1 & & & & ref \\
\hline Tw o-w ay & 0.85 & 0.00 & 0.79 & 0.92 & 0.39 & 0.00 & 0.37 & 0.41 & 0.92 & 0.12 & 0.82 & 1.02 & 1.16 & 0.00 & 1.09 & $1.25 !$ & 0.79 & 0.00 & 0.76 & 0.82 & $\downarrow \downarrow-\uparrow \downarrow$ \\
\hline One-w ay (reverse for cyclists) & & & & & 0.51 & 0.00 & 0.45 & 0.58 & & & & & 1.22 & 0.00 & 1.09 & 1.36 & 0.78 & 0.00 & 0.71 & 0.86 & $\varnothing \downarrow \varnothing \uparrow \downarrow$ \\
\hline Roadw orks & & & & & & & & & & & & & & & & & 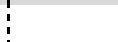 & & & & \\
\hline Normal & 1 & & & & 1 & & & & $£$ & & & & 1 & & & & $£$ & & & & ref \\
\hline Roadw orks & 5.58 & 0.00 & 3.44 & 9.06 & 0.37 & 0.00 & 0.30 & 0.46 & $\mathrm{i}$ & & & & 0.24 & 0.00 & 0.17 & $0.35 i$ & i & & & & $\uparrow \downarrow \varnothing \downarrow \varnothing$ \\
\hline Noise & 1.02 & 0.00 & 1.01 & 1.02 & 1.03 & 0.00 & 1.03 & 1.04 & 1.02 & 0.00 & 1.02 & 1.03 & 0.97 & 0.00 & 0.96 & 0.97 & 1.05 & 0.00 & 1.03 & 1.06 & $\uparrow \uparrow \uparrow \downarrow \uparrow$ \\
\hline Time elapsed (second) & 1.00003 & 0.00 & 1.00002 & 1.00003 & 1.00003 & 0.00 & 1.00002 & 1.00003 & 1.00004 & 0.00 & 1.00004 & 1.00005 & 1.00001 & 0.00 & 1.00001 & 1.00002 & 1.00001 & 0.00 & 1.00000 & 1.00001 & $\uparrow \uparrow \uparrow \uparrow \uparrow$ \\
\hline - Gender & & & & & & & --- & & $\therefore---$ & & & & --- & -- & ----- & & -1 & (-- & $\cdots--1$ & & - \\
\hline Female & 1 & & & & 1 & & & & 1 & & & & 1 & & & & 1 & & & & ref \\
\hline Male & 1.82 & 0.06 & 0.97 & $3.41 i$ & 0.68 & 0.28 & 0.34 & $1.37 i$ & 1.65 & 0.48 & 0.41 & $6.62 i$ & 0.60 & 0.34 & 0.21 & $1.70 \mathrm{i}$ & 3.88 & 0.22 & 0.44 & $34.22 \mid$ & ---- \\
\hline Bike use (times per week) & & & & & & & & & 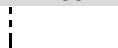 & & & & & & & & 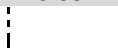 & & & & \\
\hline Five or less & 1 & & & & 1 & & & & 1 & & & & 1 & & & & $\Delta$ & & & & ref \\
\hline From 6 to 10 & 2.51 & 0.09 & 0.86 & 7.31 & 0.31 & 0.02 & 0.11 & 0.85 & 1.04 & 0.97 & 0.14 & 7.59 & 1.63 & 0.60 & 0.26 & 10.24 & 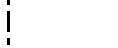 & & & & $-\downarrow--\Delta$ \\
\hline More than 10 & 1.68 & 0.34 & 0.58 & 4.85 & 0.12 & 0.00 & 0.05 & 0.29 & 0.36 & 0.19 & 0.08 & 1.67 & 1.59 & 0.47 & 0.46 & 5.46 & 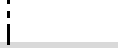 & & & & $-\downarrow--\Delta$ \\
\hline Age & 0.97 & 0.12 & 0.93 & 1.01 & 1.13 & 0.00 & 1.04 & 1.22 & 0.96 & 0.13 & 0.91 & 1.01 & 0.91 & 0.049 & 0.83 & 1.00 & 1.07 & 0.52 & 0.87 & 1.32 & $-\uparrow-\downarrow-$ \\
\hline constant & 0.04 & 0.00 & 0.01 & 0.14 & 0.01 & 0.00 & 0.00 & 0.14 & 0.12 & 0.12 & 0.01 & 1.72 & 0.35 & 0.43 & 0.03 & 4.80 & 0.01 & 0.15 & 0.00 & 5.25 & \\
\hline Individual-level variance & 0.54 & & 0.37 & 0.79 & 0.57 & & 0.39 & 0.83 & 1.37 & & 0.90 & 2.08 & 0.92 & & 0.64 & 1.32 & 3.05 & & 1.31 & 7.12 & i \\
\hline N observations & & & 3814 & & & & 3352 & & $i$ & 213 & 3685 & & & & 9950 & & 7 & & 6298 & & \\
\hline McFadden rho-squared at zero & & & 250 & & & & 679 & & 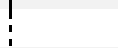 & 0.7 & 632 & & & & 051 & & 1 & & 190 & & \\
\hline McFadden rho-squared at constant & & & 035 & & & & 199 & & i & 0.0 & 038 & & & & 050 & & $i$ & & 096 & & \\
\hline C-Statistic & $\mathrm{ROC}$ & & $95 \% \mathrm{Cl}$ & & $\mathrm{ROC}$ & & $95 \% \mathrm{Cl}$ & & $\mathrm{ROC}$ & & $95 \% \mathrm{Cl}$ & & $\mathrm{ROC}$ & & $95 \% \mathrm{Cl}$ & & $\mathrm{ROC}$ & & $95 \% \mathrm{Cl}$ & & \\
\hline & 0.7524 & 0.7472 & - & 0.7577 & 0.8127 & 0.8096 & - & 0.8158 & 0.7524 & 0.7472 & - & 0.7577 & 0.7817 & 0.7778 & - & 0.7856 & 0.7307 & 0.7282 & - & 0.7331 & \\
\hline Residual ICC at constant & 0.1246 & 0.0635 & - & 0.2301 & 0.2980 & 0.1679 & - & 0.4718 & 0.4378 & 0.2564 & - & 0.6375 & 0.2469 & 0.1380 & - & 0.4019 & 0.5254 & 0.3218 & - & 0.7210 & \\
\hline Residual ICC - full model & 0.0822 & 0.0409 & - & 0.1556 & 0.0899 & 0.0443 & - & 0.1736 & 0.3633 & 0.1989 & - & 0.5673 & 0.2044 & 0.1114 & - & 0.3448 & 0.4814 & 0.2849 & - & 0.6838 & \\
\hline
\end{tabular}


Care should be taken when looking at the models for individual cities as an indication of association. The small number of participants in each city make the results vulnerable to sample selection issues. For example, if only a few of them have a more than-average inclination to experience stress (e.g. because of genetics, physical health, or other unmeasured person-specific factors), then this may affect the results. Moreover, in this sense, the ICC indicators show that the individual-level contribution to the overall variance is much higher in Houten and Amsterdam than in the other cities, suggesting that there is more unobserved heterogeneity in the sample of riders in those two cities compared to the rest. Thus, we recommend a larger number of participants per city for futures studies.

\section{Conclusions}

It can be concluded that cycling infrastructure is associated with biomarkers for stress while cycling, and the physical segregation between cyclists and vehicle drivers plays a key role in this regard. In addition, a greater probability of stress was found when a cyclist rides on a shared sidewalk, primary road, turning left or right; on cobblestones, on off-road (unpaved) surfaces, or in a noisy place. On the other hand, riding on concrete pavers, two-way streets, contra-flow streets and places with roadworks tended to reduce the likelihood of stressful events. When the cities were analysed separately, some different results were noted, although the effects for cycling infrastructure tended to be rather similar across the cities.

These findings are a useful addition to the existing literature in transport geography and urban planning about what environmental qualities promote cycling as a means of transport. The stress level along the routes, assessed directly from physiological responses, can be an important input for planning and implementation of public policies related to cycling. Therefore, aiming at a more bike-friendly city, planners and decision-makers should adopt policies based not only on environmental data or on users' data but also on the interaction between both. In addition, they could focus the interventions on the environment stressors, saving time and money, and impacting more people. In concrete terms, based on our results, interventions that reduce stressful situations in the case of intersections, for example - should be a high priority for transport planners and decision-makers seeking to promote cycling in their cities. In this sense, the European Commission, through its Guidance for Cycling Projects in the European Union, to reduce possible conflicts and increase safety and comfort for cyclists, recommends some intersection features, such as bike boxes, intersection crossing markings, two-stage bicycle turn box, refuge islands and through bike lanes to position cyclists on the correct side of turning traffic (European Commission, n.d.).

Although we have offered some speculations, we have not been able to address the causes behind the different results between the examined cities. Thus, future research on stress and urban environments should be designed to explore in depth the differences between the cities, cycling cultures and infrastructures. Considering this, we also need to explore how the associations, found in the five cities studied, would be in countries/cities with poor 
cycling infrastructure. Further studies could also be undertaken to measure the levels of stress before and after a specific change has been made to the cycling environment. Finally, in addition to the occurrence or not of stressful events, future studies may explore the magnitude and duration of stress, contributing to an even better understanding of cyclists' interaction with the environment.

\section{Acknowledgement}

This research was supported by the São Paulo Research Foundation - FAPESP (grants: 2015/50129-5; 2017/26280-0 and 2017/04460-7). The contribution from TS was made possible by funding from the Economic and Social Research Council (grant ES/N011538/1).

\section{References}

Abraham, J.E., McMillany, S., Brownlee, A.T., Hunt, J.D., 2002. Investigation of Cycling Sensitivities. Transp. Res. Board Annu. Conf. 1-10.

Aldred, R., Goodman, A., Gulliver, J., Woodcock, J., 2018. Cycling injury risk in London: A case-control study exploring the impact of cycle volumes, motor vehicle volumes, and road characteristics including speed limits. Accid. Anal. Prev. 117, 75-84.

Aldred, R., Jungnickel, K., 2014. Why culture matters for transport policy: the case of cycling in the UK. J. Transp. Geogr. 34, 78-87.

American Association of, State Highway and Transportation Officials, 2012. Guide for the Planning, Design, and Operation of Bicycle Facilities, 4 edition. ed. Washington DC.

Aumond, P., Can, A., De Coensel, B., Botteldooren, D., Ribeiro, C., Lavandier, C., 2017. Modeling Soundscape Pleasantness Using perceptual Assessments and Acoustic Measurements Along Paths in Urban Context. Acta Acust. united with Acust. 103, 430-443.

Avila-Palencia, I., De Nazelle, A., Cole-Hunter, T., Donaire-Gonzalez, D., Jerrett, M., Rodriguez, D.A., Nieuwenhuijsen, M.J., 2017. The relationship between bicycle commuting and perceived stress: A crosssectional study. BMJ Open 7.

Barratt, M., 2014. Construction Guidance Document for Contractors. London.

Bergner, B.S., 2010. Methodische und praktische Fundierung zur Etablierung des EmBaGIS: Emotionales Barriere-GIS als neues Instrument zur Identifikation und Optimierung stadträumlicher Barrieren für mobilitätseingeschränkte und behinderte Menschen - Am Anwendungsbeispiel der. TU Kaiserslautern.

Bergner, B.S., Exner, J.P., Memmel, M., Raslan, R., Talal, M., Taha, D., Zeile, P., 2013. Human Sensory Assessment Linked with Geo- and Mobile-Data Processing Methods in Urban Planning Exemplified on Different Cultures in Germany and Egypt. In: Proceedings 13th International Conference on Computers in Urban Planning and Urban Management (CUPUM). Utrcht, pp. 1-18.

Beyel, S., Wilhelm, J., Mueller-kett, C., Zeile, P., Klein, U., 2016. Stresstest städtischer Infrastrukturen - ein Experiment zur Wahrnehmung des Alters im öffentlichen Raum. In: SCHRENK, M., POPOVICH, V. V., ZEILE, P., ELISEi, P., BEYER, C. (Eds.), REAL CORP 2016. Wien, pp. 689-698.

Broach, J., Dill, J., Gliebe, J., 2012. Where do cyclists ride? A route choice model developed with revealed preference GPS data. Transp. Res. Part A Policy Pract. 46, 1730-1740. 
Brüde, U., Larsson, J., 1993. Models for predicting accidents at junctions where pedestrians and cyclists are involved. How well do they fit? Accid. Anal. Prev. 25, 499-509.

Caviedes, A., Figliozzi, M., Le, H., Liu, F., Feng, W., 2017. What does stress real-world cyclists? In: Transportation Research Board 96th Annual Meeting. Washington, pp. 1-15.

Chuang, K.-H., Hsu, C.-C., Lai, C.-H., Doong, J.-L., Jeng, M.-C., 2013. The use of a quasi-naturalistic riding method to investigate bicyclists' behaviors when motorists pass. Accid. Anal. Prev. 56, 32-41.

de Geus, B., Degraeuwe, B., Vandenbulcke, G., Panis, L.I., Thomas, I., Aertsens, J., De Weerdt, Y., Torfs, R., Meeusen, R., 2014. Utilitarian Cycling in Belgium: A Cross-Sectional Study in a Sample of Regular Cyclists. J. Phys. Act. Heal. 11, 884-894.

Dekoninck, L., Botteldooren, D., Int Panis, L., 2013. An instantaneous spatiotemporal model to predict a bicyclist's Black Carbon exposure based on mobile noise measurements. Atmos. Environ. 79, 623-631.

Doorley, R., Pakrashi, V., Byrne, E., Comerford, S., Ghosh, B., Groeger, J.A., 2015. Analysis of heart rate variability amongst cyclists under perceived variations of risk exposure. Transp. Res. Part F Traffic Psychol. Behav. 28, 40-54.

EU’s Intelligent Energy., 2010. PRESTO Cycling Policy Guide - Cycling infrastructure.

European Commission, n.d. Guidance for Cycling Projects in the European Union [WWW Document]. URL https://ec.europa.eu/transport/themes/urban/cycling/guidance-cycling-projects-eu/cyclingmeasures/intersections_en (accessed 7.22.20).

Filipan, K., De Coensel, B., Aumond, P., Can, A., Lavandier, C., Botteldooren, D., 2019. Auditory sensory saliency as a better predictor of change than sound amplitude in pleasantness assessment of reproduced urban soundscapes. Build. Environ. 148, 730-741.

Fitch, D.T., Sharpnack, J., Handy, S., 2017. The Road Environment and Bicyclists' Psychophysiological Stress. In: Proceedings of the 6th Annual International Cycling Safety Conference. Davis, pp. 22-24.

Garder, P., Leden, L., Pulkkinen, U., 1998. Measuring the safety effect of raised bicycle crossings using a new research methodology. Transp. Res. Rec. 1360, 64-70.

Garrard, J., Rose, G., Lo, S.K., Kai, S., 2008. Promoting transportation cycling for women: the role of bicycle infrastructure. Prev. Med. (Baltim). 46, 55-9.

Gattis, J.L., Watts, A., 1999. Urban street speed related to width and functional class. J. Transp. Eng. 125, 193200.

Haile, L., Gallagher, M., J. Robertson, R., 2014. The Affective Response to Exercise. In: Perceived Exertion Laboratory Manual. Springer New York, New York, NY, pp. 29-40.

Healey, J.A., Picard, R.W., 2005. Detecting Stress During Real-World Driving Tasks Using Physiological Sensors. IEEE Trans. Intell. Transp. Syst. 6, 156-166.

Hosmer, D.W., Lemeshow, S., 2000. Applied Logistic Regression, 2nd editio. ed. John Wiley \& Sons, Inc, New York.

Hunt, J.D., Abraham, J.E., 2007. Influences on bicycle use. Transportation (Amst). 34, 453-470.

Jacobsen, P.L., Ragland, D.R., Komanoff, C., 2015. Safety in Numbers for walkers and bicyclists: exploring the mechanisms. Inj. Prev. 21, 217-220. 
Kaplan, S., Prato, C.G., 2016. “Them or Us”: Perceptions, cognitions, emotions, and overt behavior associated with cyclists and motorists sharing the road. Int. J. Sustain. Transp.

Kim, J.-K., Kim, S., Ulfarsson, G.F., Porrello, L.A., 2007. Bicyclist injury severities in bicycle-motor vehicle accidents. Accid. Anal. Prev. 39, 238-251.

Kreibig, S.D., 2010. Autonomic nervous system activity in emotion: A review. Biol. Psychol. 84, 394-421.

Kyriakou, K., Resch, B., Sagl, G., Petutschnig, A., Werner, C., Niederseer, D., Liedlgruber, M., Wilhelm, F., Osborne, T., Pykett, J., 2019. Detecting Moments of Stress from Measurements of Wearable Physiological Sensors. Sensors 19, 3805.

Litman, T., Blair, R., Demopoulos, B., Eddy, N., Fritzel, A., Laidlaw, D., Maddox, H., Forster, K., 2009. Pedestrian and Bicycle Planning Guide to Best Practices Appendices. Victoria.

Liu, F., Figliozzi, M., Caviedes, A., Le, H., Mai, L., Liu, F.; Figliozzi, M., 2016. Utilizing Egocentric Video and Sensors to Conduct Naturalistic Bicycling Studies, Transportation Research and Education Center. Portland.

Lovallo, W.R., 2015. Stress and health biological and psychological interactions. SAGE, Thousand Oaks.

Lusk, A.C., Furth, P.G., Morency, P., Miranda-Moreno, L.F., Willett, W.C., Dennerlein, J.T., 2011. Risk of injury for bicycling on cycle tracks versus in the street. Inj. Prev. 17, 131-5.

Lusk, A.C., Morency, P., Miranda-Moreno, L.F., Willett, W.C., Dennerlein, J.T., 2013. Bicycle guidelines and crash rates on cycle tracks in the United States. Am. J. Public Health 103, 1240-8.

McCorry, L.K., 2007. Physiology of the autonomic nervous system. Am. J. Pharm. Educ. 71, 78.

Methorst, R., Schepers, P., Kamminga, J., Zeegers, T., Fishman, E., 2017. Can cycling safety be improved by opening all unidirectional cycle paths for cycle traffic in both directions? A theoretical examination of available literature and data. Accid. Anal. Prev. 105, 38-43.

Miranda-Moreno, L.F., Strauss, J., Morency, P., 2011. Disaggregate Exposure Measures and Injury Frequency Models of Cyclist Safety at Signalized Intersections. Transp. Res. Rec. J. Transp. Res. Board 2236, 74-82.

Misra, A., Watkins, K., Le-Dantec, A.C., 2015. Socio-demographic influence on rider type self classification with respect to bicycling. In: 94th Annual Meeting of the Transportation Research Board TRB.

Moritz, W.E., 1998. Adult Bicyclists in the United States: Characteristics and Riding Experience in 1996. Transp. Res. Rec. J. Transp. Res. Board 1636, 1-7.

Nuñez, J.Y.M., Teixeira, I.P., Rodrigues da Silva, A.N., Zeile, P., Dekoninck, L., Botteldooren, D., 2018. The influence of noise, vibration, cycle paths, and period of day on stress experienced by cyclists. Sustainability 10,1-14.

Oja, P., Titze, S., Bauman, A., de Geus, B., Krenn, P., Reger-Nash, B., Kohlberger, T., 2011. Health benefits of cycling: a systematic review. Scand. J. Med. Sci. Sports 21, 496-509.

Oja, P., Vuori, I., Paronen, O., 1998. Daily walking and cycling to work: their utility as health-enhancing physical activity. Patient Educ. Couns. 33, S87-94.

Oken, B.S., Chamine, I., Wakeland, W., 2015. A systems approach to stress, stressors and resilience in humans. Behav. Brain Res. 282, 144-154.

Olieman, M., Marin-Perianu, R., Marin-Perianu, M., 2012. Measurement of dynamic comfort in cycling using 
wireless acceleration sensors. Procedia Eng. 34, 568-573.

Papastefanou, G., 2008. Ambulatorisches Assessment und Empirische Sozialforschung.

Sozialwissenschaftlicher Fachinformationsd. soFid 11-20.

Pritchard, R., 2018. Revealed preference methods for studying bicycle route choice - a systematic review. Int. J. Environ. Res. Public Health 15.

Public Health England, 2014. Everybody Active, Every Day An evidence-based approach to physical activity. London.

Pucher, J., Buehler, R., 2012. City Cycling. The MIT Press, Cambridge, Massachusetts, London, England.

Pucher, J., Buehler, R., 2016. Safer Cycling Through Improved Infrastructure. Am. J. Public Health 106, 20892091.

Reynolds, C.C.O., Harris, M.A., Teschke, K., Cripton, P.A., Winters, M., 2009. The impact of transportation infrastructure on bicycling injuries and crashes: a review of the literature. Environ. Health 8, 47.

Rodgers, G.B., 1997. Factors associated with the crash risk of adult bicyclists. J. Safety Res. 28, 233-241.

Rodrigues da Silva, A.N., Zeile, P., Aguiar, F.O., Papastefanou, G., Bergner, B.S., 2014. Smart sensoring and barrier free planning - project outcomes and recent developments. In: Pinto, N.N., Tenedório, J.A., Antunes, A.P., Cladera, J.R. (Eds.), Technologies for Urban and Spatial Planning: Virtual Cities and Territories. Hershey, pp. 93-112.

Saelens, B.E., Sallis, J.F., Frank, L.D., 2003. Environmental correlates of walking and cycling: Findings from the transportation, urban design, and planning literatures. Ann. Behav. Med. 25, 80-91.

Schepers, P., Twisk, D., Fishman, E., Fyhri, A., Jensen, A., 2017. The Dutch road to a high level of cycling safety. Saf. Sci. 92, 264-273.

Sener, I.N., Eluru, N., Bhat, C.R., 2009. An analysis of bicycle route choice preferences in Texas, US. Transportation (Amst). 36, 511-539.

Singh, D., Kumari, N., Sharma, P., 2018. A Review of Adverse Effects of Road Traffic Noise on Human Health. Fluct. Noise Lett. 17, 1830001.

Stewart, G., Anokye, N.K., Pokhrel, S., 2015. What interventions increase commuter cycling? A systematic review. BMJ Open 5, 1-9.

Stinson, M., Bhat, C.R., 2003. Commuter Bicyclist Route Choice: Analysis Using a Stated Preference Survey. Transp. Res. Rec. 1828, 107-115.

Strauss, J., Miranda-Moreno, L.F., Morency, P., 2013. Cyclist activity and injury risk analysis at signalized intersections: A Bayesian modelling approach. Accid. Anal. Prev. 59, 9-17.

Suetomi, T., Niibe, T., 2002. A human interface design of multiple collision warning system. In: 9th World Congress on Intelligent Transport Systems. Chicago, p. 9.

Summala, H., Pasanen, E., Räsänen, M., Sievänen, J., 1996. Bicycle accidents and drivers' visual search at left and right turns. Accid. Anal. Prev. 28, 147-153.

Teixeira, I.P., Rodrigues da Silva, A.N., Manzato, G.G., 2019. Technology contributions to a conceptual framework for modelling cyclists' stress. In: 16th Nternational Conference on Computers in Urban Planning and Urban Management. Wuhan, pp. 273-286. 
Teschke, K., Harris, M.A., Reynolds, C.C.O., Winters, M., Babul, S., Chipman, M., Cusimano, M.D., Brubacher, J.R., Hunte, G., Friedman, S.M., Monro, M., Shen, H., Vernich, L., Cripton, P.A., 2012. Route infrastructure and the risk of injuries to bicyclists: a case-crossover study. Am. J. Public Health 102, 2336-43.

Thomas, B., DeRobertis, M., De Robertis, M., DeRobertis, M., 2013. The safety of urban cycle tracks: A review of the literature. Accid. Anal. Prev. 52, 219-227.

Ulrich-Lai, Y.M., Herman, J.P., 2009. Neural regulation of endocrine and autonomic stress responses. Nat. Rev. Neurosci. 10, 397-409.

Useche, S., Montoro, L., Alonso, F., Oviedo-Trespalacios, O., Useche, S., Montoro, L., Alonso, F., OviedoTrespalacios, O., 2018. Infrastructural and Human Factors Affecting Safety Outcomes of Cyclists. Sustainability 10, 299.

Van Mead, N., 2016. Bike jams and unwritten rules: a day with Amsterdam's new "bicycle mayor" [WWW Document]. Guard. URL https://www.theguardian.com/cities/2016/aug/11/cycling-amsterdam-bikejams-bicycle-mayor-anna-luten (accessed 11.27.18).

Vanparijs, J., Panis, I., Meeusen, R., de Geus, B., Int Panis, L., Meeusen, R., de Geus, B., 2015. Exposure measurement in bicycle safety analysis: A review of the literature. Accid. Anal. Prev. 84, 9-19.

Villarejo, M.V., Zapirain, B.G., Zorrilla, A.M., 2012. A Stress Sensor Based on Galvanic Skin Response (GSR) Controlled by ZigBee. Sensors 12, 6075-6101.

Wang, Chau, C.K., Ng, w y, Leung, T. m, 2016. A review on the effects of physical built environment attributes on enhancing walking and cycling activity levels within residential neighborhoods. Cities 50, 115.

Wang, H., Palm, M., Chen, C., Vogt, R., Wang, Y., 2016. Does bicycle network level of traffic stress (LTS) explain bicycle travel behavior? Mixed results from an Oregon case study. J. Transp. Geogr. 57, 8-18.

Wang, Y., Nihan, N.L., 2004. Estimating the risk of collisions between bicycles and motor vehicles at signalized intersections. Accid. Anal. Prev. 36, 313-321.

Wardman, M., Tight, M., Page, M., 2007. Factors influencing the propensity to cycle to work. Transp. Res. Part A Policy Pract. 41, 339-350.

Williams, T., 2015. Investigating Characteristics in a Spatial Context That Contribute to Where Bicycle Accidents Occur. Lincoln University, Australia.

Winters, M., Davidson, G., Kao, D., Teschke, K., 2011. Motivators and deterrents of bicycling: comparing influences on decisions to ride. Transportation (Amst). 38, 153-168.

Yang, T.-C., Matthews, S.A., 2010. The role of social and built environments in predicting self-rated stress: A multilevel analysis in Philadelphia. Heal. Place 16, 803-810.

Zee, Z. Van der, 2015. How Amsterdam became the bicycle capital of the world [WWW Document]. Guard. URL https://www.theguardian.com/cities/2015/may/05/amsterdam-bicycle-capital-world-transportcycling-kindermoord (accessed 11.27.18).

Zeile, P., Resch, B., Loidl, M., Petutschnig, A., 2016. Urban Emotions and Cycling Experience-Enriching Traffic Planning for Cyclists with Human Sensor Data. In: GI_Forum J. Geogr. Inf. Sci. pp. 204-216.

Zhang, B., 2018. Stress Recognition from Heterogeneous Data. Université de Lorraine. 


\section{TECHNICAL APPENDIX}

\section{Stress biomarker processing}

The evaluation process is based on work by Papastefanou (2008), the developer of the Smartband used; Bergner (2010), who first utilized it for Impaired People and adapted it for pedestrian use; Zeile et al. (2016) for bicycle use; and the work of Beyel et al. (2016), who transferred the Matlab evaluation process to R. Based on this process, Kyriakou et al. (2019) proofed, enriched and redeveloped the data processing for detecting moments of stress and also added spatiotemporal analysis in the proposed workflow. An overview of the data processing workflow, as described in a study by Beyel et al. (2016), is presented in Figure A1. The input data of the GPS logger are provided including information about the position and time of the recording every second. The sensor wristband measures and stores skin conductivity (scr) and temperature (temp) data.

After the data is successfully imported into a computer, a threshold value representing the minimum difference between the smallest and largest measured values is used to check whether the data sets are suitable for evaluation. This is because the Smartband also fails in some cases, for example if the contact pressure of the diodes is too weak, a solder joint comes loose or the humidity is too high. In this case, the band then provides continuous values for SCL or ST, which are constantly at "1024" or "0". This "minimum difference" is required in the workflow as a work step so that we can exclude the possibility of a recording error. Afterwards, artefacts are removed from the skin conductivity and temperature measurements. This is done by comparing each measured value with the arithmetic mean of the nearest 250 measured values (125 time steps each before and after the value to be tested). If the difference is greater than the previously defined threshold value (skin response level $=25$, skin temperature $=15)$, the tested value is replaced by the mean value. Then the frequency of 10 Hertz - this means ten measurements per second - is converted into $1 \mathrm{~Hz}$ by forming the arithmetic mean. Next, we determine the gradient between the individual points and obtain other values with a local polynomial kernel regression. This is the "smoothing process" of the measured values by means of a kernel density estimator (Gaussian kernel), specifying the degree and bandwidth so that the increases and decreases in the data may be identified more easily. After the smoothing process, a scoring points are awarded on this basis. These describe an increase, decrease or remain the same as a value compared to the previous value.

The following rules are used for the "scoring system" (Bergner, 2010, page 184):

- $\quad$ electric skin response level increases - value $=+1$;

- $\quad$ electric skin response level decreases - value $=-1$;

- $\quad$ electric skin response level remains the same - value $=0$;

- $\quad$ skin temperature increases - value $=-1$; 
- $\quad$ skin temperature decreases - value $=+1$;

- $\quad$ skin temperature remains the same - value $=0$.

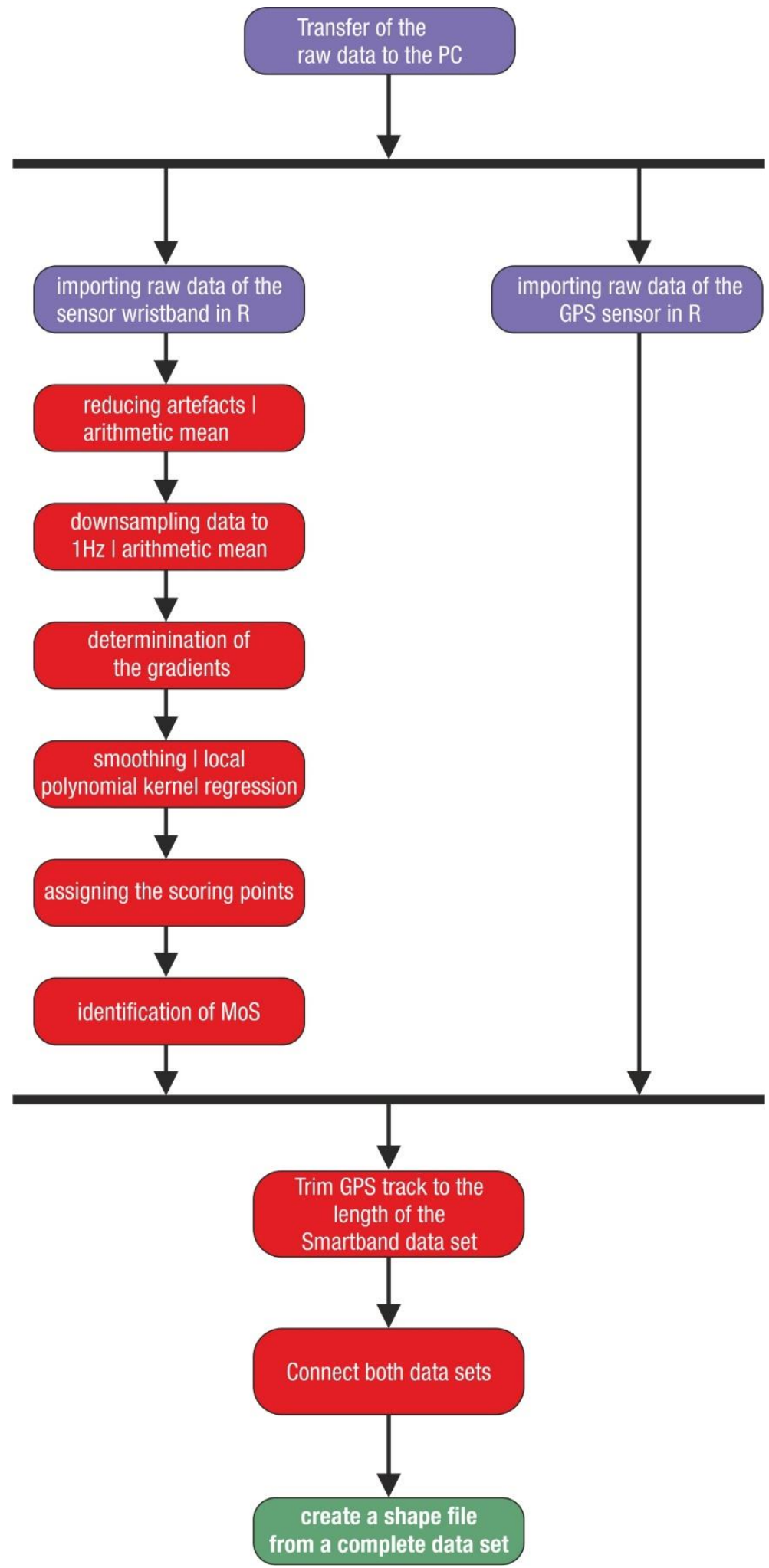

Figure A1: Workflow of data processing of GPS and SensorBand raw data in R (own figure, adapted from Beyel et al., 2016). 
For the detection of negative arousal, it is only necessary to know whether the skin conductance response level is increasing (i.e. the scoring value for this event is " +1 ") and the skin temperature has to decline (i.e. the scoring value is “ -1 "). At the end of the evaluation, two binary-coded columns have to be interpreted (see Figure A2). Scoring points will be integrated into a matrix calculation function in $\mathrm{R}$, which identified the trigger, the starting point of a stress event (i.e. the Moment of Stress - MOS). The seconds that the reaction lasts (Seconds of Stress - SOS) are identified as the stress reaction duration. The criterion to define the end of stress reaction is when electrodermal activity has scoring -1 or skin temperature +1 .

A stress event is identifiable if a signal shows decreasing skin temperature three seconds after the skin response level has risen significantly (Papastefanou, 2008). In addition, Kyriakou et al. (2019, p. 11) supported the 10 seconds for only one MOS approach during their research with the following rule: "Only one MOS in a time window of $10 \mathrm{~s}$ is detectable. This assumption is related to the typical values of latency, rise time and half recovery time $(1-5,1-5,1-10$, respectively). We used the mean values, and we argued that a stress event has an average duration of $10 \mathrm{~s}$. This argument implies that if a MOS is detected at time $t$, it is not feasible to detect another from t to $t+10$ ". However, it is possible to have SOS events that last more than 10 seconds. Therefore, after having identified the trigger (i.e. the starting point of a stress event), we also identified the following seconds in which the participants were under stress. Finally, the outcome was categorized dichotomously as either "under a stressful event" or "normal condition".
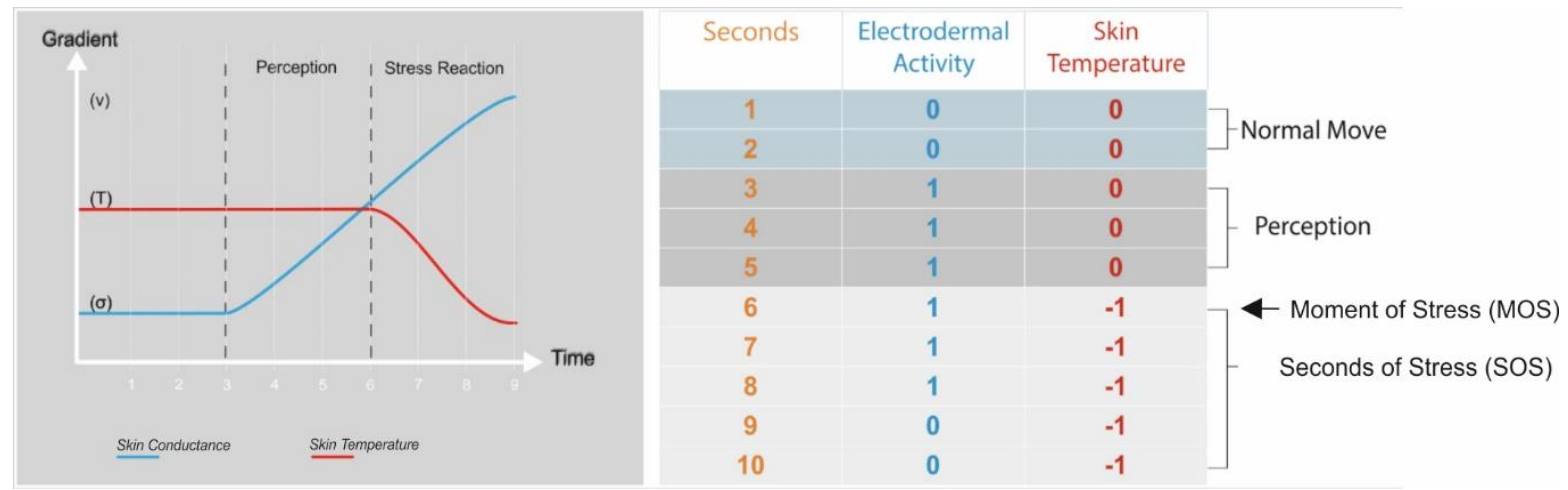

Figure A2: Typical course of physiological measurement of skin conductance (blue) and skin temperature (red) (left-hand side), scoring and 3-second delay pattern of stress reaction, with -1 scoring of skin temperature, the MOS is detected (adapted from Bergner et al., 2013) 